\title{
Opposing Roles for Hoxa2 and Hoxb2 in Hindbrain Oligodendrocyte Patterning
}

\author{
Andrés Miguez, ${ }^{1,2,3}$ Sébastien Ducret, ${ }^{4}$ Thomas Di Meglio, ${ }^{4}$ Carlos Parras, ${ }^{1,2,3}$ Hatem Hmidan, ${ }^{1,2,3}$ Céline Haton, ${ }^{1,2,3}$ \\ Sowmya Sekizar, ${ }^{1,2,3}$ Abdelkrim Mannioui, ${ }^{1,2,3}$ Marie Vidal, ${ }^{1,2,3}$ Aurélien Kerever, ${ }^{1,2,3}$ Omar Nyabi, ${ }^{5}$ Jody Haigh, ${ }^{5}$ \\ Bernard Zalc, ${ }^{1,2,3,6}$ Filippo M. Rijli, ${ }^{4,7}$ and Jean-Léon Thomas ${ }^{1,2,3,6,8}$ \\ ${ }^{1}$ Université Pierre and Marie Curie-Paris 6, Centre de Recherche de l'Institut du Cerveau et de la Moelle épinière, 75013 Paris, France, ${ }^{2}$ Institut National de \\ la Santé et de la Recherche Médicale, Unité Mixte de Recherche S 975, 75013 Paris, France, ${ }^{3}$ Centre National de la Recherche Scientifique, Unité Mixte de \\ Recherche 7225, 75013 Paris, France, ${ }^{4}$ Friedrich Miescher Institute for Biomedical Research, 4058 Basel, Switzerland, ${ }^{5}$ Department for Molecular \\ Biomedical Research, Vlaams Instituut voor Biotechnologie, and Department of Biomedical Molecular Biology, Ghent University, B-9052 Ghent, Belgium, \\ ${ }^{6}$ Assistance Publique-Hôpitaux de Paris, Groupe Hospitalier Pitié-Salpêtrière, 75013 Paris, France, ${ }^{7}$ University of Basel, CH-4003 Basel, Switzerland, and \\ ${ }^{8}$ Yale School of Medicine, Department of Neurology, New Haven, Connecticut 06520-8018
}

Oligodendrocytes are the myelin-forming cells of the vertebrate CNS. Little is known about the molecular control of region-specific oligodendrocyte development. Here, we show that oligodendrogenesis in the mouse rostral hindbrain, which is organized in a metameric series of rhombomere-derived (rd) territories, follows a rhombomere-specific pattern, with extensive production of oligodendrocytes in the pontine territory $(\mathrm{r} 4 \mathrm{~d})$ and delayed and reduced oligodendrocyte production in the prepontine region $(\mathrm{r} 2 \mathrm{~d}, \mathrm{r} 3 \mathrm{~d})$. We demonstrate that segmental organization of oligodendrocytes is controlled by Hox genes, namely Hoxa2 and Hoxb2. Specifically, Hoxa2 loss of function induced a dorsoventral enlargement of the Olig2/Nkx2.2-expressing oligodendrocyte progenitor domain, whereas conditional Hoxa2 overexpression in the Olig2 ${ }^{+}$ domain inhibited oligodendrogenesis throughout the brain. In contrast, Hoxb2 deletion resulted in a reduction of the pontine oligodendrogenic domain. Compound Hoxa2 $2^{-/-} / \mathrm{Hoxb2}^{-/-}$mutant mice displayed the phenotype of Hoxb2 $2^{-/-}$mutants in territories coexpressing Hoxa2 and Hoxb2 (rd3, rd4), indicating that Hoxb2 antagonizes Hoxa2 during rostral hindbrain oligodendrogenesis. This study provides the first in vivo evidence that Hox genes determine oligodendrocyte regional identity in the mammalian brain.

\section{Introduction}

Oligodendrocytes are the myelin-forming cells of the CNS. Despite an apparent similitude of the myelin sheath, oligodendrocytes and their precursors differ by a number of criteria, such as physiological properties, growth-factor dependency, migration

\section{Received Feb. 23, 2012; revised 0ct. 4, 2012; accepted 0ct. 5, 2012}

Author contributions: F.M.R. and J.-L.T. designed research; A. Miguez, S.D., T.D.M., C.P., H.H., C.H., S.S., A. Mannioui, and M.V. performed research; A.K., O.N., and J.H. contributed unpublished reagents/analytic tools; A. Miguez and B.Z. analyzed data; A. Miguez, F.M.R., and J.-L.T. wrote the paper.

This work was supported by Institut National de la Santé et de la Recherche Médicale (J.-L.T.), Novartis Research Foundation (F.M.R.), Fédération pour la Recherche sur le Cerveau (J.-L.T., F.M.R.), Fondation pourL'Aide à la Recherche sur la Sclérose En Plaques (J.-L.T., F.M.R., A. Miguez), Agence Nationale Recherche (08-BLAN-0162-01, J.-L.T., C.H.), Swiss National Science Foundation (Sinergia CRSI33_127440) (F.M.R.), Boehringer Ingelheim Fonds (A. Miguez), and Neuroscience pole of research in lle de France (C.H.). T.D.M. is recipient of a European Molecular Biology Organization long-term fellowship. A. Miguez was a recipient of a grant from a European Cooperation in Science and Technology network while he was working at F.M.R.'s laboratory. We thank D. Rowitch for the gift of the Olig2-tvaCre mouse line. Nkx2.2 and Islet1/2 antibodies, developed by T.M. Jessell and S. Brenner-Morton, and Nkx6.1 antibody, developed by 0.D. Madsen, were obtained from the Developmental Studies Hybridoma Bank developed under the auspices of the National Institute of Child Health and Human Development and maintained by the University of lowa, Department of Biological Sciences, lowa City, lowa. Probes for in situ hybridization were kindly provided by the following colleagues: D. Rowitch (Olig1/2), R. DiLauro (Nkx2.2), P. Gruss (Pax6), and F. Guillemot (Ngn2).

Correspondence should be addressed to any of the following: Dr. Bernard Zalc, Institut National de la Santé et de la Recherche Médicale, Unité Mixte de Recherche S 975, 75013 Paris, France, E-mail: bernard.zal@@upmc.fr; Dr. Filippo M. Rijli, Friedrich Miescher Institute for Biomedical Research, Maulberstrasse 66, 4058 Basel, Switzerland, E-mail: filippo.rijli@fmi.ch; or Dr. Jean-Léon Thomas, Yale School of Medicine, Department of Neurology, New Haven, CT 06520-8018, E-mail: jean-leon.thomas@yale.edu.

DOI:10.1523/JNEUROSCI.0885-12.2012

Copyright $\odot 2012$ the authors $\quad 0270-6474 / 12 / 3217172-14 \$ 15.00 / 0$ pathways, and their different sites of origin along the neural tube (Spassky et al., 1998, 2001; Kessaris et al., 2006; Káradóttir et al., 2008; Tripathi et al., 2011). During development, multiple subpopulations of oligodendrocyte precursor cells (OPCs) are generated in successive waves from different domains along the dorsoventral (DV) axis of the neural tube (Richardson et al., 2006; Rowitch and Kriegstein, 2010). In the spinal cord and hindbrain, OPCs first arise ventrally, adjacent to the midline (Noll and Miller, 1993; Davies and Miller, 2001). In the mouse, the ventral wave of oligodendrogenesis starts at embryonic day (E) 11.5E13.5 (Timsit et al., 1995; Pringle et al., 1996). From E13.5, additional subpopulations of OPCs develop in the lateral and dorsal plates following a ventrodorsal temporal sequence (Cai et al., 2005; Fogarty et al., 2005; Vallstedt et al., 2005; Sugimori et al., 2007).

The identity of OPCs is determined, at least in part, by the expression of transcription factors, such as Olig1/2, Nkx2.2, or Sox10, that have been characterized along the DV axis of the neural tube (Rowitch, 2004; Wegner, 2008). Dorsally, the Olig2 ${ }^{+}$ domain is abutting the $\mathrm{Pax}^{+}$progenitor territory, whereas ventrally it is bordered by the $\mathrm{Nkx} 2.2+$ progenitor domain, except in the rostral hindbrain where Olig2 ${ }^{+}$and $\mathrm{Nkx} 2.2^{+}$progenitor domains almost completely overlap (Vallstedt et al., 2005).

A role for rostrocaudal (RC) positional determinants in oligodendroglial identity has not yet been explored. We have chosen the mouse hindbrain, which is transiently compartmentalized 
along the RC axis into seven or eight rhombomeres (r) (Lumsden and Krumlauf, 1996). Hindbrain oligodendrocytes have been the focus of only a few reports describing similarities between hindbrain and spinal cord oligodendrogenesis (Ono et al., 1997; Davies and Miller, 2001; Vallstedt et al., 2005).

Hox transcription factors show spatially restricted expression patterns during early neurogenesis and appear as prime candidates as RC positional determinants (Lumsden and Krumlauf, 1996). The Hox gene family comprises 39 members, which are organized in four clusters. Each cluster contains a series of paralog genes (Hox PG1Hox PG13). Hox PG2 genes, namely Hoxa2 and Hoxb2, are activated in neural progenitors during hindbrain segmentation (for review, see Narita and Rijli, 2009). Functional studies in the mouse have shown that Hox PG2 genes are involved in the control of rhombomere-specific neuronal patterning, migration, and connectivity (Davenne et al., 1999; Oury et al., 2006; Geisen et al., 2008).

Here, to investigate a possible role of Hox PG2 genes in oligodendrogenesis, we focus on the rostral hindbrain, where Hox PG2 genes display their main patterning role (Narita and Rijli, 2009). We provide in vivo evidence that Hox PG2 genes confer an RC segmental identity to rostral hindbrain OPCs. Moreover, we found that Hoxa2 and Hoxb2 have opposing roles, namely repressing and promoting oligodendrogenesis, respectively. These findings indicate that a tight regulation of the balance between Hox PG2 gene activities is required for proper RC oligodendrocyte patterning in the rostral hindbrain.

\section{Materials and Methods}

Generation of the ROSA::(lox-STOP-lox)Hoxa2-IRES-EGFP mouse line. The conditional Hoxa2 overexpression mouse line was generated by using the Gateway-compatible ROSA26 locus targeting vector as previously described (Nyabi et al., 2009). LR reactions were performed between the plasmid pENTR-FLAG-Hoxa2 (containing the Hoxa2 cDNA coding sequence with a 5 'FLAG tag) and the destination vector pROSA26-DV1 to obtain the targeting vector pROSA26-FLAG-Hoxa2-IRES-EGFP. This vector was linearized with PvuI and electroporated into the E14 embryonic stem (ES) cell line. The positive ES cell clones, selected by G418 resistance and screened by PCR, were aggregated with morula-stage embryos obtained from inbred (C57BL/ $6 \times \mathrm{DBA} / 2)$ F1 mice. Germline transmission of the ROSA26:: (lox-STOP-lox)Hoxa2-IRES-EGFP allele was obtained. Heterozygous and homozygous mice were viable and fertile.

Generation of a conditional Hoxb2 mutant allele and Hoxb2-null mouse line. To generate a Hoxb2 mutant allele suitable for conditional knockout studies, we used a strategy based on both Cre-mediated (Gu et al., 1993) and Flp-mediated (Dymecki, 1996) recombination to generate a selection marker-free locus flanked by recombinase-specific sites. A neocassette driven by the phosphoglycerate kinase (PGK) promoter was inserted in the Hoxb2 intron, 950 bp downstream of the translational start codon. The PGK-neo cassette was flanked by two Frt sites for Flpmediated excision and a loxP site immediately following the $3^{\prime}$ Frt site. A second loxP site was also introduced in the Hoxb2 3'UTR, 468 bp downstream of the Hoxb2 translational stop codon, for Cre-mediated conditional deletion. Thus, neither the loxP sites nor the Frt-flanked PGK-neo cassette interrupted the Hoxb2 coding sequence. Homologous recombination of the targeting vector was obtained in ES cells and confirmed by Southern blot, PCR, and sequencing analysis. Germline transmission of the Hoxb2 (Frt-neo-Frt)lox allele was obtained, and heterozygous mutant mice were viable and fertile. In vivo Flp-mediated excision of the PGKneo cassette was obtained by mating the Hoxb2 $2^{(F r t-n e o-F r t) l o x}$ allele to the ACTB:FLPe deleter to obtain the Hoxb2 $2^{\text {flox }}$ allele (Rodríguez et al., 2000). Following germline transmission of the Hoxb2 flox allele to the progeny, correct excision of the selection marker cassette was confirmed by PCR and sequencing. Hoxb flox/+ and Hoxb2 $2^{\text {flox/flox }}$ mutant mice were produced at Mendelian frequency, had no obvious abnormalities, were fertile, and survived a normal lifespan. To obtain a Hoxb2null allele, a $C M V:: C r e$ transgenic deleter (Dup é et al., 1997) was mated to Hoxb2 flox/+ mutant mice. The ensuing Hoxb2 $2^{\text {del/+ }}$ progeny had no obvious abnormalities, were fertile, and survived a normal lifespan. Hoxb $2^{\text {del/del }}$ homozygous-null mutants were generated by crossing Hoxb $2^{\text {del/+ }}$ heterozygotes.

Generation of Hoxa2/Hoxb2-deficient mice. Hoxb2 $2^{\text {del/+ }}$ mice were crossed with Hoxa2 $2^{E G F P+/-}$ mice to obtain double heterozygous mutant animals. Hoxb2 $2^{\text {del/+ }} ;$ Hoxa $2^{E G F P+/-}$ mice were mated to obtain Hoxa2/ Hoxb2 homozygous-null mutants.

Mouse strains, tamoxifen treatment, and genotyping. OF1 wild-type mice were obtained from Charles River. The following mouse strains were used: Hoxa2 $2^{\text {EGFP(lox-neo-lox) }}$, Hoxa2 $^{\text {EGFP+/- }}$, and Hoxa2 $2^{\text {flox }}$ (Pasqualetti et al., 2002; Ren et al., 2002); CMV-ßactin-CreERT2 (Santagati et al., 2005); Olig2-tva-Cre (Schüller et al., 2008; gift from D. Rowitch, University of California, San Francisco). For tamoxifen (Tx) treatments, Tx was provided by oral gavage $(10 \mathrm{mg} / 30-40 \mathrm{~g}$ of body weight) into pregnant mice at day 10.5 of gestation, according to Santagati et al. (2005). All genotypes were confirmed by PCR of tail DNA using specific primers. Noon of the plug day was considered as E0.5 and mice of either sex were used. All animal studies were performed in accordance with the guidelines issued by the French Ministry of Agriculture and Swiss cantonal authorities.

Reagents. Antibodies used were anti-Pax6 (polyclonal rabbit, 1:500, Covance), anti-Olig2 (polyclonal rabbit, 1:200, Millipore), anti-Nkx2.2 [monoclonal mouse, 1:2, Developmental Studies Hybridoma Bank (DSHB)], anti-Nkx6.1 (mouse, 1:400, DSHB), anti-Islet 1:2 (mouse, 1:200, DSHB), anti-PDGF receptor $\alpha$ (anti-PDGFR $\alpha$ ) (rat, 1:400, BD Biosciences), anti-phospho-histone 3 (mouse, 1:500, Millipore), antiGFP (chick, 1:2000, Aves Labs), anti-CNPase (mouse, 1:500, Millipore), anti-5HT (rabbit, 1:1000, Sigma-Aldrich), anti-Sox9 (rabbit, 1:1000, gift from M. Wegner), anti-Sox10 (guinea pig, 1:1000, gift from M. Wegner), anti-Pax3 (mouse, 1:100, gift from F. Relaix), anti-Pax7 (mouse, 1:10, gift from F. Relaix), and anti-O4 (mouse, 1:4, gift from I. Sommer). Fluorescent secondary antibodies were Alexa Fluor 488, Alexa Fluor 594, and Alexa Fluor 647 Ig (1:1000, Invitrogen). Hoxa2 and Hoxb2 riboprobes were previously described (Hunt et al., 1991).

Immunohistochemistry and in situ hybridization. Embryonic brains were fixed by immersion in $4 \%$ paraformaldehyde in $0.12 \mathrm{~m}$ phosphate buffer, $\mathrm{pH}$ 7.4 (PFA). Brain cryosections were blocked in 10\% fetal bovine serum in PBS containing $0.3 \%$ Triton X-100 and incubated overnight at room temperature with primary antibodies, followed by species-specific secondary antibodies. Whole hindbrain explants were dissected out in a PBS/0.6\% glucose solution, opened dorsally, and fixed in PBS containing 4\% PFA before immunostaining. For cryosections, cell nuclei were stained by incubation with Hoechst and slides were mounted with Fluoromount (Southern Biotechnologies Associates). Hindbrain explants were mounted with ProLong (Invitrogen). In situ hybridizations were performed as described in Spassky et al. (1998).

Image acquisition and quantifications. Image acquisition was performed using a fluorescence macroscope (MacroFluo Z6/Z16 APO, Leica), a fluorescence microscope equipped with the apotome system (AxioImager Z1, Zeiss), and a brightfield microscope equipped with a CCD camera (DFC 360FX/420C, Leica). The size of the Olig2 ventricular domain on hindbrain flat-mounts was measured using ImageJ software for digital tracing. The number of ventral Olig $2^{+}$and PDGFR $\alpha^{+}$cells on sagittal cryosections was evaluated as the average number of labeled cells counted on five successive sagittal sections ( $20 \mu \mathrm{m}$ each) on one side of the floor plate (see Figs. 3, 4, 6). The number of $\mathrm{PH}^{+}$and $\mathrm{PH}^{+}$/ PDGFR $\alpha^{+}$cells were counted similarly. The number of ventral PDGFR $\alpha^{+}$cells in the forebrain was counted on six successive coronal sections (overall thickness, $300 \mu \mathrm{m}$ ) in the anterior entopeduncular area/ medial ganglionic eminence region (see Fig. 3). The percentage of Olig2 ${ }^{+}$migrating cells (see Figs. 3,6 ) was calculated with Prism software by comparing integrated intensity of the migrating zone with that of the ventricular zone, as previously described (Di Lullo et al., 2011).

Statistical analyses. GraphPad Prism software was used for statistical analysis. Data were compared using Student's $t$ test, unless otherwise specified. Significant $p$ values are indicated in figure legends. All error bars represent SEM. 


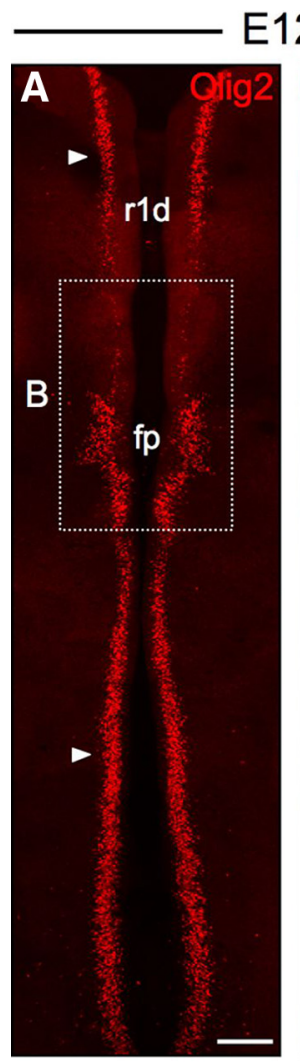

\section{E12.5}
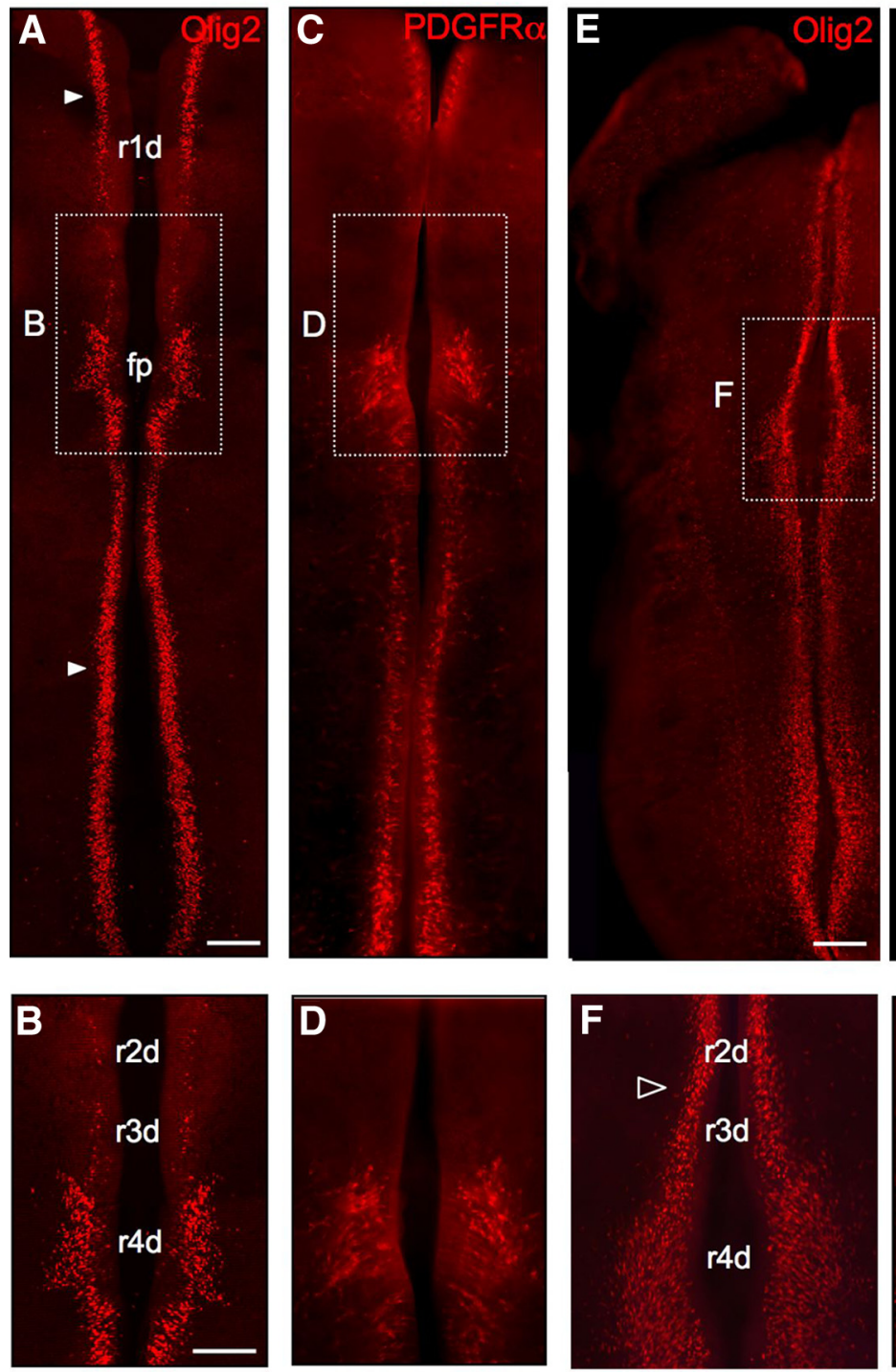

E13.5
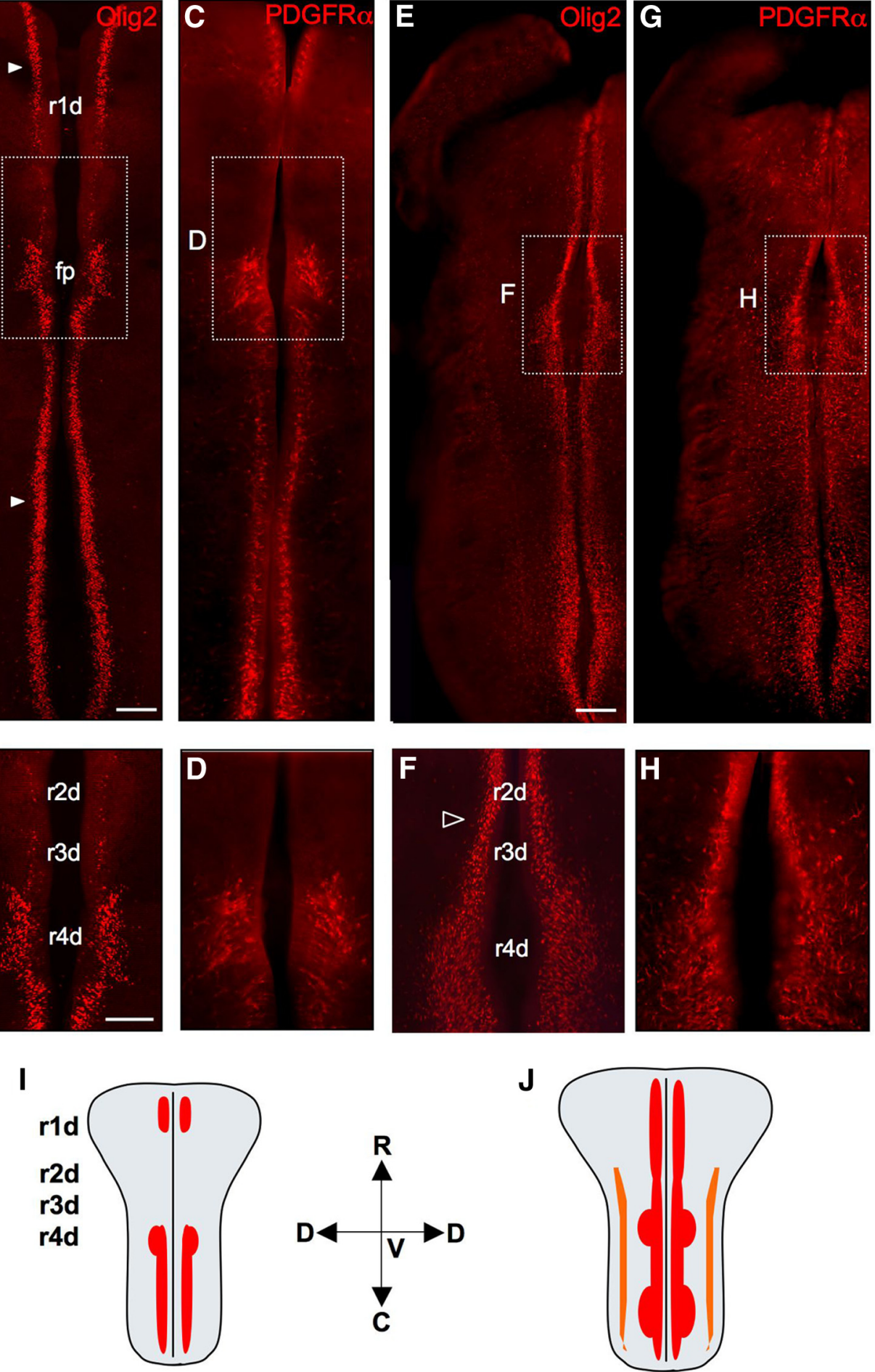

Figure 1. Segmental pattern of oligodendrogenesis in the developing hindbrain. Hindbrain flat-mounts from E12.5 and E13.5 wild-type embryos labeled for Olig2 and PDGFR $\alpha$. A-D, At E12.5, ventral 0lig2-expressing and PDGFR $\alpha$-expressing cells are found at the rhombomesencephalic boundary ( $\mathrm{r} 1 \mathrm{~d}$ ), rare or absent in r2d-r3d domains, expanded in $\mathrm{r} 4 \mathrm{~d}$, and, from r $5 \mathrm{~d}$, they form two bilateral columns extending toward the spinal cord. $\boldsymbol{E}-\boldsymbol{H}$, From E13.5 onwards, both ventral and dorsal (not visible at low magnification) pools of 0lig2 ${ }^{+} /$PDGFR $\alpha^{+}$cells extend along the entire rostrocaudal length of the hindbrain. $\boldsymbol{I}, \boldsymbol{J}$, Schematic representation of flat-mounted hindbrains showing the spatiotemporal pattern of oligodendrogenesis at E12.5 $(\boldsymbol{I})$ and E13.5 $(\boldsymbol{J})$, with both ventral (red) and dorsal (orange) pools of OPCS. R, Rostral; C, caudal; V, ventral; D, dorsal; r(n)d, rhombomere-derived domain; fp, floor plate. Scale bars: $\boldsymbol{A}, \boldsymbol{C}, \boldsymbol{E}, \mathbf{G}, 300 \mu \mathrm{m} ; \boldsymbol{B}, \boldsymbol{D}, \boldsymbol{F}, \boldsymbol{H}, 100 \mu \mathrm{m}$.

\section{Results}

Segmental pattern of oligodendrogenesis in the developing hindbrain

We set out to study the onset of hindbrain oligodendrogenesis with antibodies against Olig2 and PDGFR $\alpha$, which are early markers of oligodendrocyte lineage (Rowitch, 2004). Flat-mount hindbrain preparations were examined at developmental stages E12.5 and E13.5 (i.e., when the first hindbrain OPCs arise) (Vallstedt et al., 2005). At E12.5, Olig2 ${ }^{+}$cells showed a bilateral and discontinuous pattern of distribution in the ventral neuroepithelium. Along the RC 

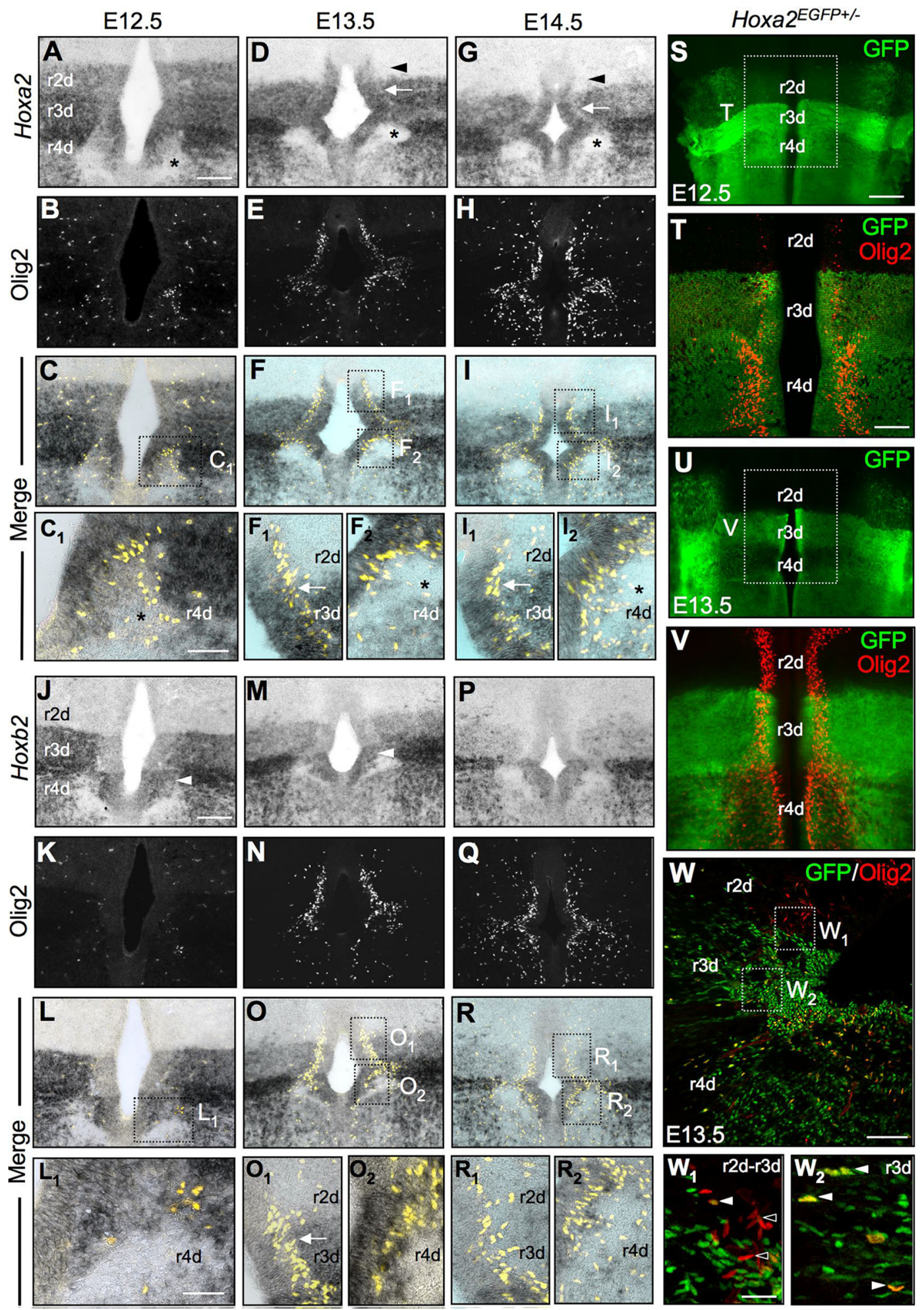

Figure 2. Hox PG2 expression in the Olig2 domain of the developing rostral hindbrain. $\boldsymbol{A}-\boldsymbol{R}$, Hindbrain coronal cryosections from E12.5-E14.5 wild-type embryos at the r2d-r4d level, double labeled with anti-0lig2 antibody and an antisense riboprobe specific for Hoxa2 ( $\boldsymbol{A}-\boldsymbol{I})$ and $H o x b 2(\boldsymbol{J}-\boldsymbol{R})$ transcripts (Fig. $7 F$, position of section plan on a lateral view of hindbrain). $\boldsymbol{A}-\boldsymbol{F}$, From E12.5 to E13.5, Hoxa2 expression is downregulated in the prepontine r2d region, especially in the parenchyma ( $\boldsymbol{D}$, arrowhead), correlating with the extension of Olig2 expression in this domain. $\mathbf{G}-\mathbf{I}$, From E13.5 to E14.5, Hoxa2 expression regresses in the prepontine and pontine regions, especially in $\mathrm{r} 2 \mathrm{~d}$ ( $G$, arrowhead) and $\mathrm{rd}$, while 0 lig2 ${ }^{+}$cells expand in these domains. At all developmental stages examined, 0 lig2 ${ }^{+}$cells form among Hoxa2-expressing progenitors, but they concentrate at the external edge of ventricular domain $(\boldsymbol{B}, \boldsymbol{E}, \boldsymbol{H})$ and within territories where Hoxa2 expression is downregulated $\left(\boldsymbol{D}, \boldsymbol{G}, \boldsymbol{F}_{1}, \boldsymbol{I}_{1}\right.$, arrows). $\boldsymbol{C}_{1}, \boldsymbol{F}_{1} \boldsymbol{F}_{2}, \boldsymbol{I}_{1} \boldsymbol{I}_{2}$, High magnifications of frames in $\boldsymbol{C}, \boldsymbol{F}$, and $\boldsymbol{I}$. Olig2 ${ }^{+}$cells include both Hoxa2-expressing cells in the ventricular layer $\left(\boldsymbol{I}_{2}\right)$ and Hoxa2-negative cells, which are predominantly $\mathrm{OPCs}$ migrating in the subventricular layer and descending axonal tracts $\left(\boldsymbol{C}_{1}, \boldsymbol{F}_{2}, \boldsymbol{I}_{2}\right)$. Asterisks in $\mathbf{D}, \mathbf{G}, \boldsymbol{C}_{1}, \boldsymbol{F}_{2}$, and $\boldsymbol{I}_{\mathbf{2}}$ indicate descending axonal tracts. J-R, Hoxb2 transcripts were not detected in the $\mathrm{r} 2 \mathrm{~d}$ territory and showed the highest level of expression in $\mathrm{r} 4 \mathrm{~d}(\boldsymbol{J}, \boldsymbol{M}, \boldsymbol{P})$. Arrowheads in $\boldsymbol{J}$ and $\boldsymbol{M}$ indicate the lateral extension of the Hoxb2-expressing ventricular domain in $\mathrm{r} 4 \mathrm{~d}$. $\boldsymbol{K}-\boldsymbol{R}, 0$ lig $2^{+}$cells include few Hoxb2-expressing cells, especially localized in the ventricular layer of $\mathrm{r} 4 \mathrm{~d}\left(\boldsymbol{L}_{\mathbf{1}}, \mathbf{0}, \mathbf{0}_{\mathbf{1}}, \mathbf{O}_{\mathbf{2}}\right)$, but mainly concentrate at the external ventricular edge where Hoxb2 expression is downregulated $\left(\mathbf{0}_{\mathbf{1}}\right.$, arrow). The majority of migrating OPCs do not express Hoxb2 at E13.5 and E14.5 $\left(\boldsymbol{R}_{1}, \boldsymbol{R}_{1}, \boldsymbol{R}_{\mathbf{2}}\right) . \boldsymbol{L}_{\mathbf{1}}, \mathbf{0}_{\mathbf{1}}, \mathbf{0}_{\mathbf{2}}, \boldsymbol{R}_{\mathbf{1}}, \boldsymbol{R}_{2}$, High magnifications of frames in $\boldsymbol{L}, \mathbf{0}$, and $\boldsymbol{R}$. S- $\boldsymbol{V}$, Hindbrain flat-mounts from Hoxa2 ${ }^{\text {EGFP+/- }}$ embryos double labeled with antibodies against GFP (green) and Olig2 (red). From E12.5 to E13.5, the level (Figure legend continues.) 
axis, Olig2 ${ }^{+}$cells localized at the rhombomesencephalic boundary (rld) were rare or absent in r2d-r3d domains, expanded dorsoventrally in the r4d domain, which corresponds to the presumptive pontine region, and from the r5d territory formed two bilateral columns extending toward the spinal cord (Fig. 1A,B). At E13.5, the Olig2-expressing domain had become continuous along the ventral hindbrain, although still larger in r4d than in r2d-r3d (Fig. 1E,F). A similar spatiotemporal pattern of expression was displayed by other specific oligodendroglial markers, such as PDGFR $\alpha$ (Fig. $1 C, D, G, H)$, Sox10, Olig1, and O4 (data not shown). Therefore, between E12.5 and E13.5, oligodendrocytes form in the rostral hindbrain with rhombomere-specific patterns, with a $1 \mathrm{~d}$ delay in r2d-r3d and in larger number in $\mathrm{r} 4 \mathrm{~d}$.

\section{Hox PG2 expression in the Olig2 domain of the developing rostral hindbrain}

Among Hox family members, Hox PG2 genes display the rostralmost expression domains in the CNS. Along the hindbrain RC axis, Hoxa2 and Hoxb2 have overlapping expression domains with offset rostral boundaries mapping in $\mathrm{r} 2$ and $\mathrm{r} 3$ for Hoxa2 and Hoxb2, respectively. Moreover, progenitors along the DV axis display distinct Hoxa2 and Hoxb2 expression levels (Davenne et al., 1999).

We compared Hoxa2 and Olig2 expression in the rostral hindbrain from E12.5 to E14.5, first on coronal cryosections double labeled with anti-Olig2 antibody and an antisense riboprobe specific for Hoxa2 transcripts. We observed that (1) Hoxa2 expression is progressively downregulated in the prepontine $\mathrm{r} 2 \mathrm{~d}$ region (Fig. $2 A, D, G$, arrowheads in $D$ and $G$ ), while Olig2 expression extends into this domain (Fig. $2 B, C, E, F, H, I) ;(2) \mathrm{Olig}^{+}{ }^{+}$cells appear at the dorsal edge of the ventricular progenitor domain in r3d-r4d (Fig. 2B,C,E,F,H,I) and localize in low-expressing $\mathrm{Hoxa}_{2}{ }^{+}$sites, while the ventricular domain expresses fairly high Hoxa2 transcript levels (Fig. $2 F_{1}, I_{1}$, arrows); and (3) Olig2 ${ }^{+}$cells migrate through territories where Hoxa2 expression is downregulated, such as in the descending axonal tracts in r4d (Fig. $2 C_{1}, F_{2}, I_{2}$, asterisks).

We next analyzed the expression pattern of Olig2 in Hoxa $2^{E G F P+/-}$ mice, which express the EGFP knocked-in at the Hoxa2 locus, thus faithfully mimicking the endogenous Hoxa2 expression pattern (Pasqualetti et al., 2002). Hindbrain flatmounts from Hoxa $2^{\text {EGFP+1- }}$ embryos were double labeled with antibodies against GFP and Olig2. From E12.5 to E13.5, bilateral columns of Olig2 ${ }^{+}$cells emerged at the dorsal edge of the ventralmost $\mathrm{GFP}^{+}$progenitor domain (i.e., the $\mathrm{Hoxa}^{+} / \mathrm{Nkx} 2.2^{+}$ domain) in r3d-r4d, while GFP expression levels decreased in the ventral and alar plates of $\mathrm{r} 2 \mathrm{~d}$, similar to the distribution of endogenous Hoxa2 transcripts (Fig. 2S-V). At the cellular level, more ventricular Olig2 ${ }^{+}$cells expressed GFP in the $\mathrm{r} 3 \mathrm{~d}$ than in the r2d domain (Fig. $2 W_{1}, W_{2}$ ). At E18.5, EGFP expression was expressed by the majority of $\mathrm{CNP}^{+}$mature oligodendrocytes in

\footnotetext{
$\leftarrow$

(Figure legend continued.) of Hoxa2/EGFP expression decreases in the basal plate of $\mathrm{r} 2 \mathrm{~d}$ and $\mathrm{r} 4 \mathrm{~d}$ $(\boldsymbol{S}, \boldsymbol{U})$, while bilateral columns of Olig2 ${ }^{+}$cells enlarge in these domains $(\boldsymbol{I}, \boldsymbol{V})$. Hoxa2/EGFP expression is maintained in the ventralmost ventricular domain of $r 3 \mathrm{~d}$. $\boldsymbol{W}$, Sagittal section of a Hoxa2 ${ }^{\text {EGFP+/- }}$ E13.5 embryo at the r2d-r4d level, labeled for GFP (green) and Olig2 (red). Ventricular Olig2 ${ }^{+}$cells expressing Hoxa2/EGFP were detected in $\mathrm{r} 3 \mathrm{~d}-\mathrm{r} 4 \mathrm{~d}$, but not in $\mathrm{r} 2 \mathrm{~d}$. In the subventricular layer of $\mathrm{r2d}$-r4d region, both 0 lig $2^{+} \mathrm{EGFP}^{-}$(dark arrowheads) and Olig2 ${ }^{+}$GFPP $^{+}$(white arrowheads) cells were observed, and the majority of Olig2 ${ }^{+}$cells migrating in the parenchyma were $\mathrm{GFP}^{+}\left(\boldsymbol{W}_{1}, \boldsymbol{W}_{2}\right) . r(n)$ d, rhombomere-derived domain. Scale bars: $S, \boldsymbol{U}, 200 \mu \mathrm{m} ; A--I, J--R, T, V, W, 100 \mu \mathrm{m} ; C_{1}, F_{1}, F_{2}, I_{1}, I_{2}, L_{1}, \mathbf{O}_{1}, \mathbf{O}_{2}, R_{1}, R_{2}, 50 \mu \mathrm{m} ; W_{1}$ $W_{2}, 25 \mu \mathrm{m}$
}

prepontine and pontine territories (data not shown). Altogether, these data indicate that low levels of Hoxa2 expression correlate with the expansion of Olig2 ${ }^{+}$progenitors at the onset of oligodendrogenesis.

Next, we compared the expression of Olig2 with that of the other Hox PG2 gene, Hoxb2. Coronal cryosections of hindbrain, at developmental stages E12.5, E13.5, and E14.5, were colabeled with anti-Olig2 antibody and an antisense riboprobe against Hoxb2 (Fig. $2 J-R$ ). Hoxb2 transcripts were not detected in the r2d territory, as expected from its normal expression domain. Hoxb2 and Hoxa2 were both expressed in $\mathrm{r} 3 \mathrm{~d}$ as well as in $\mathrm{r} 4 \mathrm{~d}$, which showed the highest level of Hoxb2 expression (Fig. 2J, M,P). Notably, Hoxb2 expression expanded dorsally in the r4d $N k x 2.2^{+}$ domain, where Olig2 ${ }^{+}$cells colocalized with Hoxb2-expressing progenitors, especially at E12.5-E13.5 and unlike Hoxa2 (Fig. $2 \mathrm{~J}, \mathrm{M}$, arrowheads; Fig. 2O-O $\mathrm{O}_{2}$; Davenne et al., 1999). In contrast, the majority of migrating OPCs did not appear to express Hoxb2 at E13.5 and E14.5 (Fig. 2O,R).

Altogether, the spatiotemporal patterns of Hoxa2 and Hoxb2 expression between E12.5 and E14.5 suggest their potential involvement in segment-specific patterning of the ventral Olig2 ${ }^{+}$ oligodendrocyte subpopulation.

\section{Conditional Hoxa2 overexpression in $\mathrm{Olig}{ }^{+}$cells inhibits oligodendrogenesis}

In the rostral hindbrain, Hoxa2 is expressed at low levels in Olig2 ${ }^{+}$ progenitors at the onset of oligodendrogenesis (Fig. 2C,F). Thus, one possibility is that downregulation of Hoxa2 is a prerequisite to allow the appearance of Olig2 expression at the dorsal edge of the $\mathrm{Nkx} 2.2^{+}$ domain and, in turn, to induce ventral oligodendrocyte generation. We therefore examined whether forced Hoxa2 overexpression in Olig $2^{+}$progenitors could inhibit hindbrain oligodendrogenesis. Conditional Hoxa2 overexpression was induced by mating the Olig2-tva-Cre line (Schüller et al., 2008) with a newly generated allele ROSA26::(lox-STOP-lox)Hoxa2-IRES-EGFP (hereafter referred to as Olig2-tva-Cre;ROSA $A^{(\text {lox-stop-lox)Hoxa2 }}$ mice), in which Hoxa2 is selectively activated only in the Olig2 lineage upon Cre-mediated recombination (see Materials and Methods). Hindbrain flat-mounts from E13.5 Olig2-tva-Cre;ROSA ${ }^{\text {(lox-stop-lox)Hoxa2 }}$ embryos were immunostained to detect oligodendroglial cells with antibodies against Olig2 and PDGFR $\alpha$. The dorsoventral extent of the Olig2 ${ }^{+}$ventricular domain was reduced in the r2d-r3d region, compared with ROSA $^{\text {(lox-stop-lox)Hoxa2 }}$ controls (Fig. $3 A, C, D, F, G$ ). Quantification of the number of PDGFR $\alpha^{+}$OPCs on sagittal sections confirmed that, in these conditional Hoxa2 gain-of-function mutants, ventral oligodendrogenesis was decreased by $\sim 2$-fold in the prepontine and pontine territories (r2d-r4d) (Fig. 3B,C,E,F,H). Therefore, forced Hoxa2 expression in Olig2 ${ }^{+}$cells inhibits ventral hindbrain oligodendrogenesis.

Remarkably, the Olig2 ${ }^{+} / \mathrm{PDGFR} \alpha^{+}$cell population was also reduced by $\sim 50 \%$ in Olig2-tva-Cre; ROSA ${ }^{(l o x-s t o p-l o x) H o x a 2} \mathrm{em}-$ bryos compared with controls in ectopic brain territories where Hoxa 2 is not normally expressed during development, such as the ventral forebrain [Fig. 3L-O; mean number of PDGFR $\alpha^{+}$cells per area $\left(\mathrm{mm}^{2}\right) \pm$ SEM: ROSA $A^{\text {(lox-stop-lox)Hoxa2 }}, 156.4 \pm 6.91$;

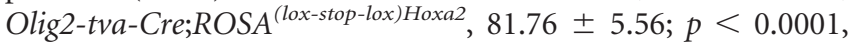
Student's $t$ test, $n=3$ ]. As shown in Figure 3P-R, EGFP, which is directly translated from the IRES of the allele overexpressing Hoxa2 (see Materials and Methods), and Olig2 expression levels are inversely correlated in ventricular forebrain progenitors. Namely, Olig2 levels are low in ectopic EGFP/Hoxa2 highly expressing cells (Fig. $3 Q, R$, dark arrowheads), while progenitors strongly expressing Olig2 display low levels of EGFP/Hoxa2 ecto- 

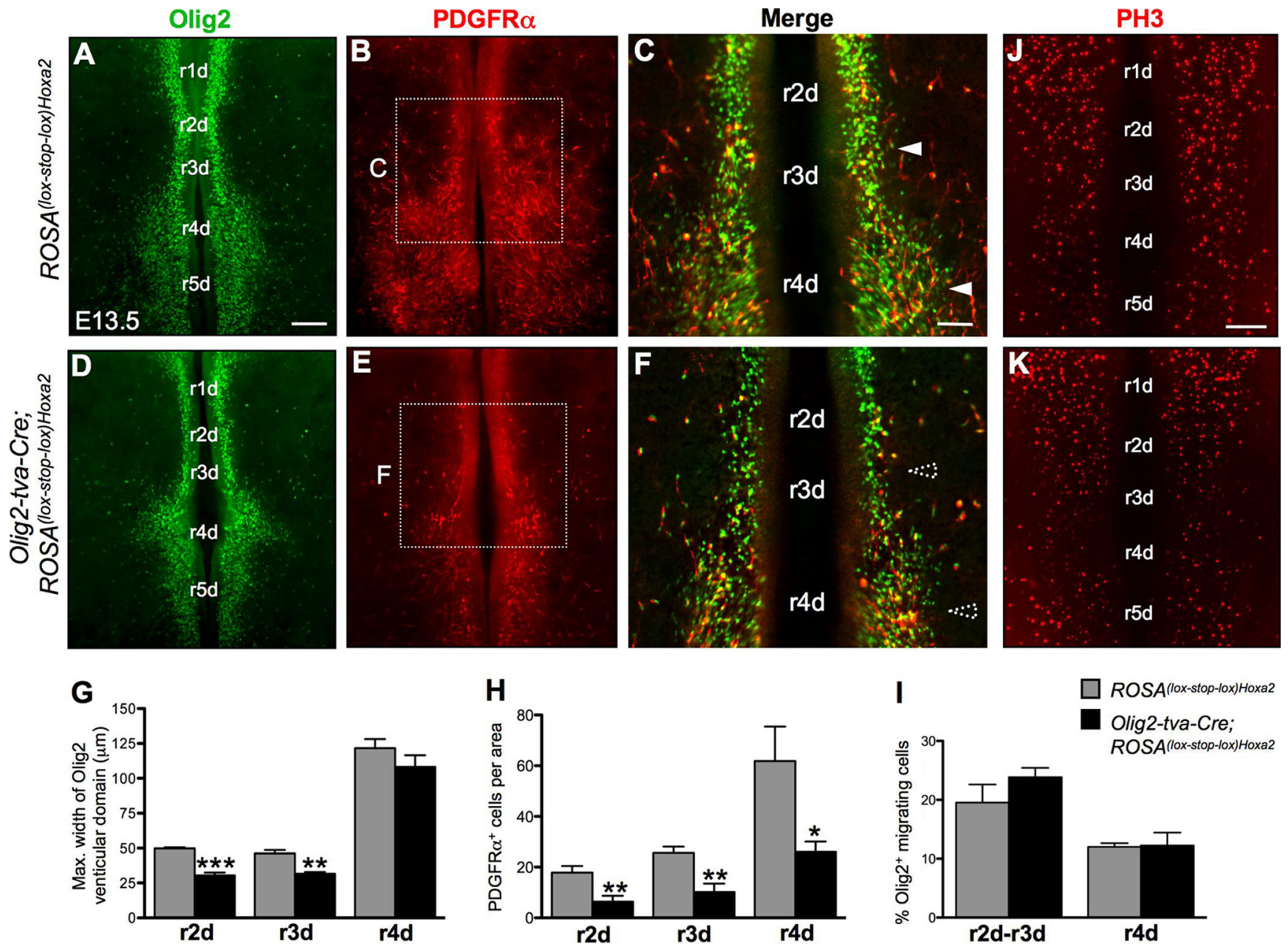

ROSA(lox-stop-lox)Hoxa2

Olig2-tva-Cre; ROSA(lox-stop-lox)Hoxa2
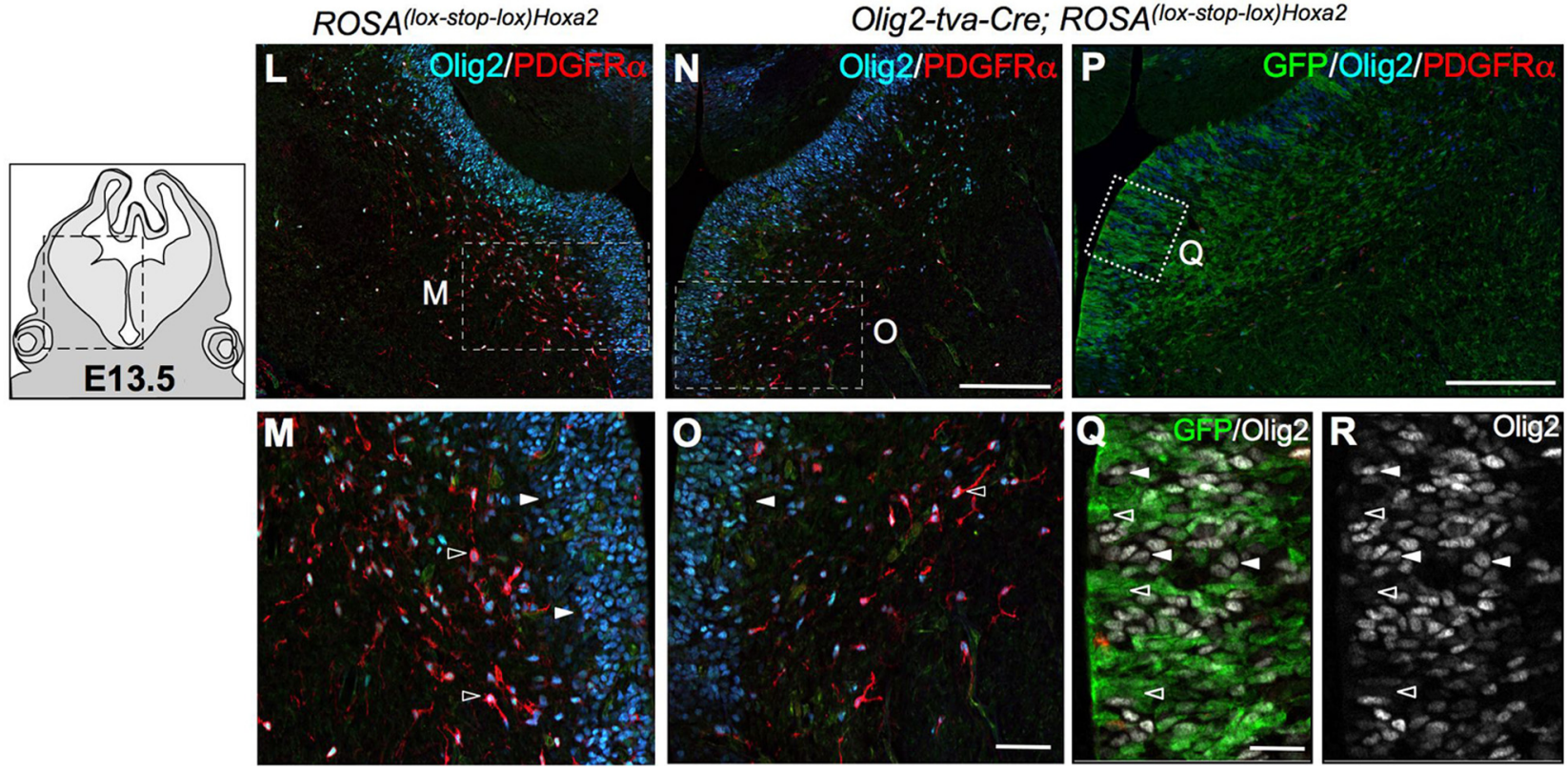

Figure 3. Conditional Hoxa2 overexpression in Olig2 ${ }^{+}$cells inhibits oligodendrogenesis. $A-I$, Hindbrain flat-mounts from ROSA $A^{(l o x-s t o p-l o x) H o x a 2}(A-C)$ and Olig2-tva-Cre; ROSA $A^{(l o x-5 t o p-l o x) H o x a 2}$ $(\boldsymbol{D}-\boldsymbol{F})$ embryos at E13.5, labeled for Olig2 (green) and PDGFR $\alpha$ (red). Hoxa2 gain of function in Olig2-expressing cells results in a reduced 0 lig2 ${ }^{+}$progenitor domain in r2d and r3d (A, C, $\left.\boldsymbol{D}, \boldsymbol{F}, \boldsymbol{G}\right)$ and a decreased number of PDGFR $\alpha^{+}$cells in the basal plate of $\mathrm{r} 2 \mathrm{~d}$, $\mathrm{r3d}$, and $\mathrm{r} 4 \mathrm{~d}(\boldsymbol{B}, \boldsymbol{C}, \boldsymbol{E}, \boldsymbol{F}, \boldsymbol{H})$. No differences between genotypes were found regarding the percentage of 0 lig2 ${ }^{+}$migrating cells $(\boldsymbol{I})$. $\boldsymbol{J}, \boldsymbol{K}$, Hindbrain flat-mounts labeled for PH3, showing that Olig2-tva-Cre; ROSA $A^{(l o x-\text {-stop-lox)Hoxa2 }}$ embryos display a decreased number of PH3 ${ }^{+}$proliferating cells, compared with control animals. $\boldsymbol{L}-\boldsymbol{R}$, Coronal sections from ROSA $A^{(l o x-s t o p-l o x) H o x a 2}(\boldsymbol{L}, \boldsymbol{M})$ and Olig2-tva-Cre; $R O S A^{(l o x-s t o p-l o x) H o x a 2}(\boldsymbol{N}-\boldsymbol{R})$ E13.5 embryos, at the level of the anterior entopeduncular area/medial ganglionic eminence of the forebrain, labeled for Olig2 (blue), PDGFR $\alpha$ (red), and GFP (green). $\boldsymbol{M}, \mathbf{0}$, The number of 0lig2 ${ }^{+}$(white arrowheads) and PDGFR $\alpha^{+}$(black arrowheads) in Olig2-tva-(re; ROSA $A^{(l o x-5 t o p-l o x) H o x a 2}$ embryos was reduced by half compared with controls. High levels of EGFP/Hoxa2 and Olig2 expression were mutually exclusive in ventricular progenitors (P). $\mathbf{Q},($ Figure legend continues.) 
pic expression (Fig. 3Q,R, white arrowheads). Thus, Hoxa2 can inhibit Olig2 expression in a cell-autonomous manner in progenitor cells throughout the brain.

We next analyzed the migration and proliferation of OPCs in hindbrain flat-mounts of E13.5 Hoxa2-gain-of-function mutants. At this stage, the Olig2 ${ }^{+}$ventricular zone is observed as two bilateral columns of dense populations of cells next to the ventral midline, while Olig2 ${ }^{+}$migrating cells disperse laterally in the ventroalar plate (Fig. $3 A, D$ ). We quantified the ratio of migrating versus ventricular/nonmigrating progenitors as a function of fluorescence intensity in respective areas, as previously reported (Di Lullo et al., 2011). Figure 3I quantifies the percentage of cells located in the migration area of the $\mathrm{r} 2 \mathrm{~d}-\mathrm{r} 3 \mathrm{~d}$ and $\mathrm{r} 4 \mathrm{~d}$ domains. The percentage of migrating Olig2 ${ }^{+}$cells was similar between Olig2-tva-Cre;ROSA ${ }^{\text {(lox-stop-lox)Hoxa2 }}$ gain-of-function mutants and ROSA $A^{\text {(lox-stop-lox)Hoxa2 }}$ controls, suggesting that OPCs' migratory properties were not altered by Hoxa2 forced expression. In contrast, cell proliferation was reduced in the ventroalar plate of r2d-r4d, as shown by immunolabeling of hindbrain flat-mounts (Fig. $3 J, K$ ) and sagittal sections with anti-phospho-histone H3 (PH3) antibody. Hoxa2 overexpression induced a decrease in the number of $\mathrm{PH}_{3}{ }^{+}$cells $\left[\right.$mean number of $\mathrm{PH}^{+}{ }^{+}$cells per area $\left(\mathrm{mm}^{2}\right) \pm$ SEM: ROSA ${ }^{\text {(lox-stop-lox)Hoxa2 }}$ (control), $35.7 \pm$ 1.9, Olig2-tva-Cre;ROSA ${ }^{\text {(lox-stop-lox)Hoxa2 }:} 14.8 \pm 1.8, p=$ 0.0004; Student's $t$ test, $n=3$ ], and less OPC proliferation (percentage of PH3 ${ }^{+} / \mathrm{PDGFR}^{+}$cells/total PDGFR $\alpha^{+}$cells \pm SEM: $\operatorname{ROSA}^{(\text {lox-stop-lox)Hoxa2 }}, \quad 7.1 \pm 1.2$, Olig2-tva-Cre; $R O S A^{(l o x-s t o p-l o x) H o x a 2}, 3.1 \pm 0.4, p=0.0346$; Student's $t$ test, $n=3$ ). These data suggest that Hoxa2 has a primary effect on the generation rather than on the migration of OPCs.

Finally, we investigated whether the reduced oligodendrogenesis induced by Hoxa2-overexpression resulted in an alteration of hindbrain oligodendrocyte population at later stages of development. We quantified OPCs $\left(\mathrm{PDGFR} \alpha^{+}\right.$) as well as cells expressing 2-cyclic nucleotide 3-phosphodiesterase (CNP), a marker for differentiated oligodendrocytes (Kim et al., 1984), on sagittal sections of hindbrain at E18.5. The number of OPCs and mature oligodendrocytes in Hoxa2gain-of-function mutants and controls were similar [mean number of PDGFR $\alpha^{+}$cells per area $\left(\mathrm{mm}^{2}\right) \pm$ SEM: r2d: ROSA ${ }^{(l o x-s t o p-l o x) H o x a 2}$ (control), $265.2 \pm 78.4 ;$ Olig2-tva-Cre;ROSA (lox-stop-lox)Hoxa2, $319.8 \pm$ 94.1; r3d: ROSA ${ }^{\text {(lox-stop-lox)Hoxa2 }}, 360.7 \pm 132.2$; Olig2-tva-Cre; ROSA $A^{(\text {lox-stop-lox)Hoxa2 }}, 419.3 \pm 134.7$; mean number of $\mathrm{CNP}^{+}$cells per area $\left(\mathrm{mm}^{2}\right):$ r2d: ROSA $A^{\text {(lox-stop-lox)Hoxa2 }}, 9.1 \pm 7.6 ;$ Olig2-tva-Cre; ROSA (lox-stop-lox)Hoxa2 $2,12.9 \pm 14.5$; r3d: ROSA $A^{\text {(lox-stop-lox)Hoxa } 2}, 9.5 \pm$ 10.9; Olig2-tva-Cre; ROSA ${ }^{(\text {lox-stop-lox)Hoxa2 }}, 30.6 \pm 37.8 ; n=3$ ]. These data suggest that the reduced oligodendrogenesis observed at E13.5 is compensated at later stages, either by additional proliferation or by increased survival of OPCs. In Hoxa2-GOF mutants, there is less competition between the remaining ventral OPCs for growth factors, such as PDGF-A, which determines the final number and distribution of mature oligodendrocytes (Calver et al., 1998), and OPCs may expand transiently more rapidly. We have tested this hypothesis at embryonic stage E16.5, between the onset of oligodendrogenesis (E12.5) and the onset of oligodendrocyte differentiation (E17.5E18.5). We found that Hoxa2-GOF mutants showed more prolifer-

$\leftarrow$

(Figure legend continued.) $\boldsymbol{R}$, Olig2 expression was weak in highly fluorescent cells (dark arrowheads), while progenitors strongly expressing Olig2 displayed a low level of GFP fluorescence (white arrowheads). $\mathrm{r}(n) \mathrm{d}$, rhombomere-derived domain. $\mathbf{G}, \mathrm{r} 2 \mathrm{~d}, p=0.0009 ; \mathrm{r3d}, p=0.0069 ; \boldsymbol{H}, \mathrm{r} 2 \mathrm{~d}, p=$ $0.0034 ; \mathrm{r3d}, p=0.0010 ; \mathrm{r} 4 \mathrm{~d}, p=0.0193 . n=3$ animals of each type. Area, $1 \mathrm{~mm}^{2}$. Scale bars: $\boldsymbol{A}, \boldsymbol{B}$, $\boldsymbol{D}, \boldsymbol{E}, \boldsymbol{J}, \boldsymbol{K}, \mathbf{L}, \mathbf{N}, \boldsymbol{P}, 100 \mu \mathrm{m} ; \boldsymbol{C}, \boldsymbol{F}, \boldsymbol{M}, \mathbf{O}, 50 \mu \mathrm{m} ; \mathbf{Q}, \mathbf{R}, 25 \mu \mathrm{m} .{ }^{*} p<0.05 ;{ }^{* *} p<0.01 ;{ }^{* * *} p<0.001$. ating OPCs in the prepontine domain than control embryos [percentage of $\mathrm{PH}^{+} / \mathrm{PDGFR} \alpha^{+}$cells/total PDGFR $\alpha^{+}$cells per section \pm SEM (r2d-r3d): Olig2-tva-Cre; ROSA ${ }^{(l o x-s t o p-l o x) H o x a 2}, 8.5 \pm$ $0.3 ;$ ROSA $^{\text {(lox-stop-lox)Hoxa2 }}, 5.8 \pm 0.2 ; p=0.0152$, Student's $t$ test, 3 sections/embryo, $n=3$ ]. Additional immunostaining for cleaved caspase-3 to detect cells undergoing apoptosis in the r2d-r3d domain revealed caspase- $3^{+}$cells, but failed to show caspase- $3^{+} / \mathrm{PDGFR} \alpha^{+}$ cells both in controls and Hoxa2-gain-of-function mutants (data not shown), suggesting that OPC survival is likely not affected by Hoxa2 overexpression. Thus, the twofold reduction in ventricular progenitors observed in Hoxa2-GOF is rapidly normalized following an additional cell cycle of OPCs before they differentiate. However, we cannot rule out the possibility that ectopic OPCs originating from other rostral and caudal progenitor domains of the neural tube may migrate into the $\mathrm{r} 2-\mathrm{r} 3$ domain and play a role in compensating for the early reduction of ventral oligodendrogenesis.

\section{Hoxa 2 inactivation results in dorsal expansion of the Olig2 progenitor domain and increased oligodendrogenesis}

To confirm the inhibitory effect of Hoxa2 on hindbrain oligodendrogenesis, we next analyzed the effect of Hoxa2 loss of function. At E13.5, Hoxa2 ${ }^{\text {EGFP - /- }}$ mutant embryos showed a dorsally expanded ventricular domain of Olig2 expression, compared with heterozygous littermates (Fig. $4 A-D$ ). Motor neuron specification appeared normal, as indicated by the pattern of Islet $1 / 2$ expression (data not shown). In contrast, $\mathrm{Hoxa}_{2}{ }^{\mathrm{EGFP-1}-}$ embryos formed twice as many PDGFR $\alpha^{+}$OPCs than controls in the r2d-r4d ventral plate (Fig. $4 E-H)$. The number of PDGFR $\alpha^{+}$OPCs was not altered in rld, as expected by the lack of Hoxa2 expression in r1 during normal development. Similar to Hoxa2 overexpression, Hoxa2 deletion did not significantly alter $\mathrm{OPC}$ migration in the $\mathrm{r} 2 \mathrm{~d}-\mathrm{r} 4 \mathrm{~d}$ region, as shown by the similar percentage of migrating OPCs in Hoxa $2^{\text {EGFP- - - }}$ mutants and Hoxa $2^{E G F P+/-}$ controls (percentage of Olig2 ${ }^{+}$migrating cells \pm SEM: r2d-r3d: Hoxa2 ${ }^{E G F P+1-}, 20.6 \pm 2.8 ;$ Hoxa2 $^{\text {EGPP-1-}}, 14.1 \pm$ $1.6 ; p=0.0690$; r4d: Hoxa2 ${ }^{\text {EGFP+/- }}, 14.6 \pm 1.6 ;$ Hoxa2 $^{\text {EGFP-I- }}$, $11.4 \pm 2.3 ; p=0.291$; Student's $t$ test, $n=4)$. Moreover, at E18.5, Hoxa $2^{\text {EGFP-1- }}$ mutants showed a similar number of OPCs and mature oligodendrocytes than control mice [mean number of PDGFR $\alpha^{+}$cells per area $\left(\mathrm{mm}^{2}\right) \pm$ SEM: r2d: Hoxa2 $2^{\text {EGFP+/- }}$ (control), $272.1 \pm 65.4 ;$ Hoxa2 $2^{\text {EGP - I- }}, 280.6 \pm 119.1$; r3d: Hoxa2 $^{\text {EGFP+/- }}, 340.5 \pm 112.2 ;$ Hoxa2 $^{\text {EGFP-/- }}, 309.7 \pm 104.8$; mean number of $\mathrm{CNP}^{+}$cells per area $\left(\mathrm{mm}^{2}\right)$ : r2d: Hoxa $^{\text {EGFP+/- }}, 8.9 \pm$ 5.6; Hoxa $2^{\text {EGFP-/- }}, 11.2 \pm 10.1$; r3d: Hoxa2 ${ }^{\text {EGFP+/- }}, 11.4 \pm 10.2$; Hoxa $\left.2^{E G F P-1-}, 23.8 \pm 24.1\right]$. Thus, the loss of Hoxa2 function has an early impact on the onset of oligodendrogenesis, which can be compensated at later developmental stages.

Hoxa2 inhibits ventral oligodendrogenesis by spatially restricting the dorsal extent of oligodendrocyte generation in r2d-r4d territories and thus, ultimately, limiting the size of the Olig2 ${ }^{+}$domain. Indeed, previous studies showed DV rhombomere patterning defects in Hoxa2 mutants as early as E10.5 (Davenne et al., 1999). We anticipated that in Hoxa2-deficient embryos such DV pattern defects may persist through later stages and have direct consequences on the patterning of the Olig2 progenitor domain. Thus, we examined the expression of DV patterning genes implicated in oligodendrogenesis and neurogenesis, including Pax6, Nkx2.2, Nkx6.1, and Ngn2. In E13.5 Hoxa $2^{\text {EGFP-1- }}$ mutant embryos, the transcript levels and expression patterns of all these genes were altered in the rostral hindbrain, compared with control heterozygotes (Fig. 5A-L). Namely, the expression domains of Nkx2.2 (Fig. 5A,B,G,H) and Olig2 (Fig. $5 G-L$ ) in the r2d-r4d ventral plate were dorsally extended. Pax6 expression was decreased in $\mathrm{r} 2 \mathrm{~d}-\mathrm{r} 4 \mathrm{~d}$, with a dorsal 
Hoxa2EGFP-/
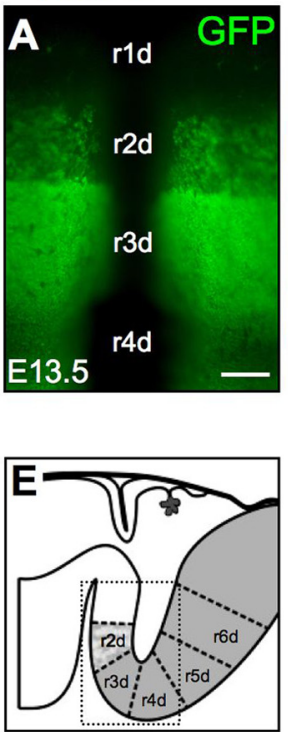

E13.5
Hoxa2EGFP+/
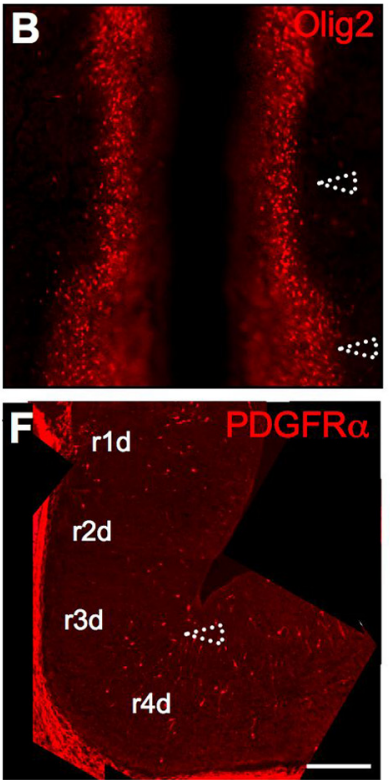

Hoxa2EGFP-/-
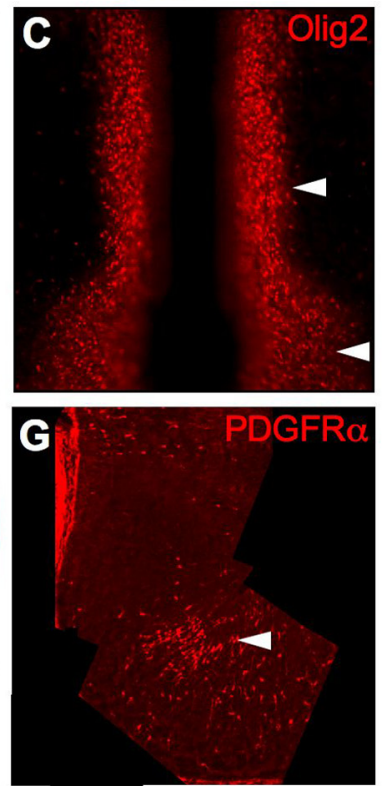
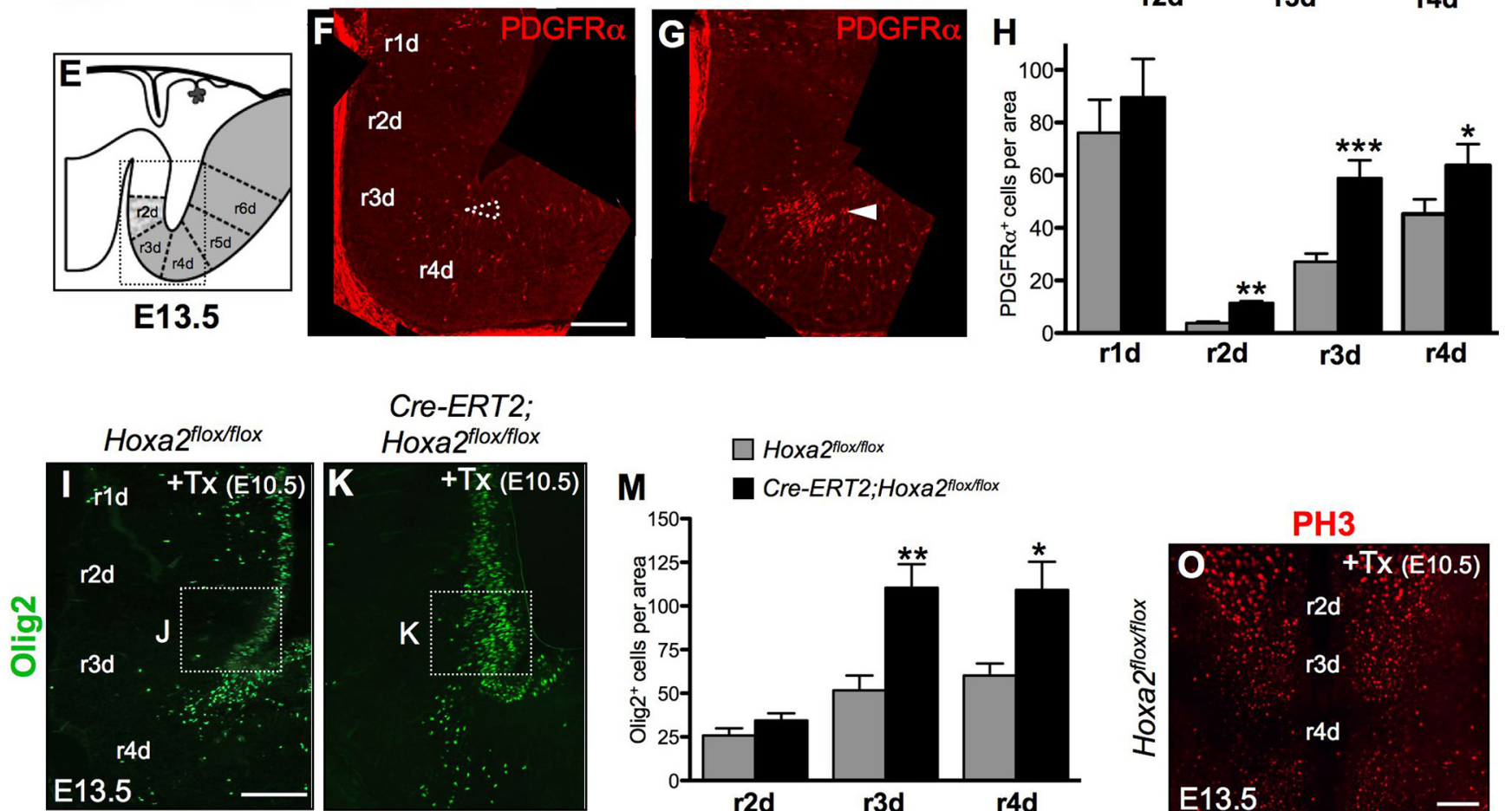

Cre-ERT2;


Figure 4. Hoxa2 deletion increases oligodendrogenesis in the rostral hindbrain. $\boldsymbol{A}-\boldsymbol{H}$, Hindbrain flat-mounts $(\boldsymbol{A}-\boldsymbol{C})$ and sagittal sections $(\boldsymbol{E}-\boldsymbol{G})$ from Hoxa2 ${ }^{E G F P+/-}(\boldsymbol{B}, \boldsymbol{F})$ and $H o x a 2^{E G F P}-/-(\boldsymbol{A}$, $\boldsymbol{C}, \boldsymbol{G})$ embryos at E13.5, labeled for GFP (green) and Olig2 or PDGFR $\alpha$ (red). Hoxa2-deficient mice show an enlarged Olig2 ${ }^{+}$progenitor domain $(\boldsymbol{C}, \boldsymbol{D})$ and an increased number of PDGFR $\alpha^{+}$OPCS

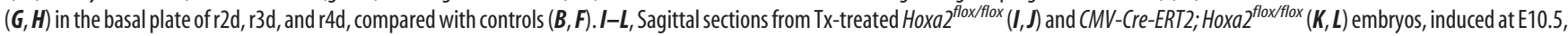
sacrificed at E13.5, and immunolabeled for Olig2 (green) and PDGFR $\alpha$ (red). Tx-induced Hoxa2 knockout embryos display an increased number of 0lig2 ${ }^{+}(\boldsymbol{K}, \boldsymbol{M})$ and PDGFR $\alpha^{+}(\boldsymbol{L}, \boldsymbol{N})$ cells in the basal plate of $\mathrm{r} 3 \mathrm{~d}$ and $\mathrm{r} 4 \mathrm{~d}$, compared with control animals $(\boldsymbol{I}, \boldsymbol{J})$. White and black arrowheads indicate 0 lig2 ${ }^{+}$cells and PDGFR $\alpha^{+}$cells, respectively, in $\boldsymbol{J}$ and $\boldsymbol{L} . \mathbf{O}, \boldsymbol{P}$, Hindbrain flat-mounts from

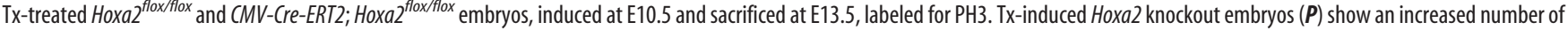
$\mathrm{PH}^{+}{ }^{+}$cells in the basal plate of $\mathrm{r} 2 \mathrm{~d}-\mathrm{r} 3 \mathrm{~d}$, compared with control mice $(\boldsymbol{O})$. $\mathrm{r}(n) \mathrm{d}$, rhombomere-derived domain. $\boldsymbol{D}, \mathrm{r2d}, p=0.0009 ; \mathrm{r} 3 \mathrm{~d}, p=0.0044 ; \mathrm{r} 4 \mathrm{~d}, p<0.0001 ; n=4$ animals of each type; $\boldsymbol{H}, \mathrm{r} 2 \mathrm{~d}, p=0.00397 ; \mathrm{r3d}, p=0.000133 ; \mathrm{r} 4 \mathrm{~d}, p=0.0370 ; n=6$ animals of each type; $\boldsymbol{M}, \mathrm{r3d}, p=0.0014 ; \mathrm{rd} \mathrm{d}, p=0.0131 ; \boldsymbol{N}, \mathrm{r} 3 \mathrm{~d}, p=0.011 ; \mathrm{r} 4 \mathrm{~d}, p=0.036 ; n=7$ animals of each type. Area, $1 \mathrm{~mm}^{2}$. Scale bars: $\boldsymbol{F}, \mathbf{G}, \mathbf{I}, \boldsymbol{K}, 200 \mu \mathrm{m} ; \boldsymbol{A}-\mathbf{C}, \mathbf{O}, \boldsymbol{P}, 100 \mu \mathrm{m} ; \boldsymbol{J}, \mathbf{L}, 80 \mu \mathrm{m} .{ }^{*} p<0.05 ;{ }^{* *} p<0.01 ;{ }^{* *} p<0.001$.

shift of its ventral border (Fig. 5C,D,I,J). Similarly, the ventral border of the Nkx6.1 ${ }^{+}$domain was shifted dorsally in r2d-r3d (Fig. 5E,F). The expression levels of the proneural gene Ngn2 were also reduced in $\mathrm{r} 2 \mathrm{~d}-\mathrm{r} 4 \mathrm{~d}$, with a dorsal extension of its ventral ventricular domain (Fig. $5 K, L$ ). In contrast, no expression abnormalities were observed for Pax 3 and Pax7 in the dorsal plate of
Hoxa $2^{\text {EGFP-I- }}$ embryos (data not shown). Thus, Hoxa2 inhibits the dorsal extension of the Olig $2^{+} / N k \times 2.2^{+}$domain in the ventral plate by restricting the dorsoventral extent of bHLH and homeodomain (HD) transcription factors regulating oligodendrogenesis, such as Pax6, Nkx6.1, and Ngn2 (Fig. 5M,N, summary model). 

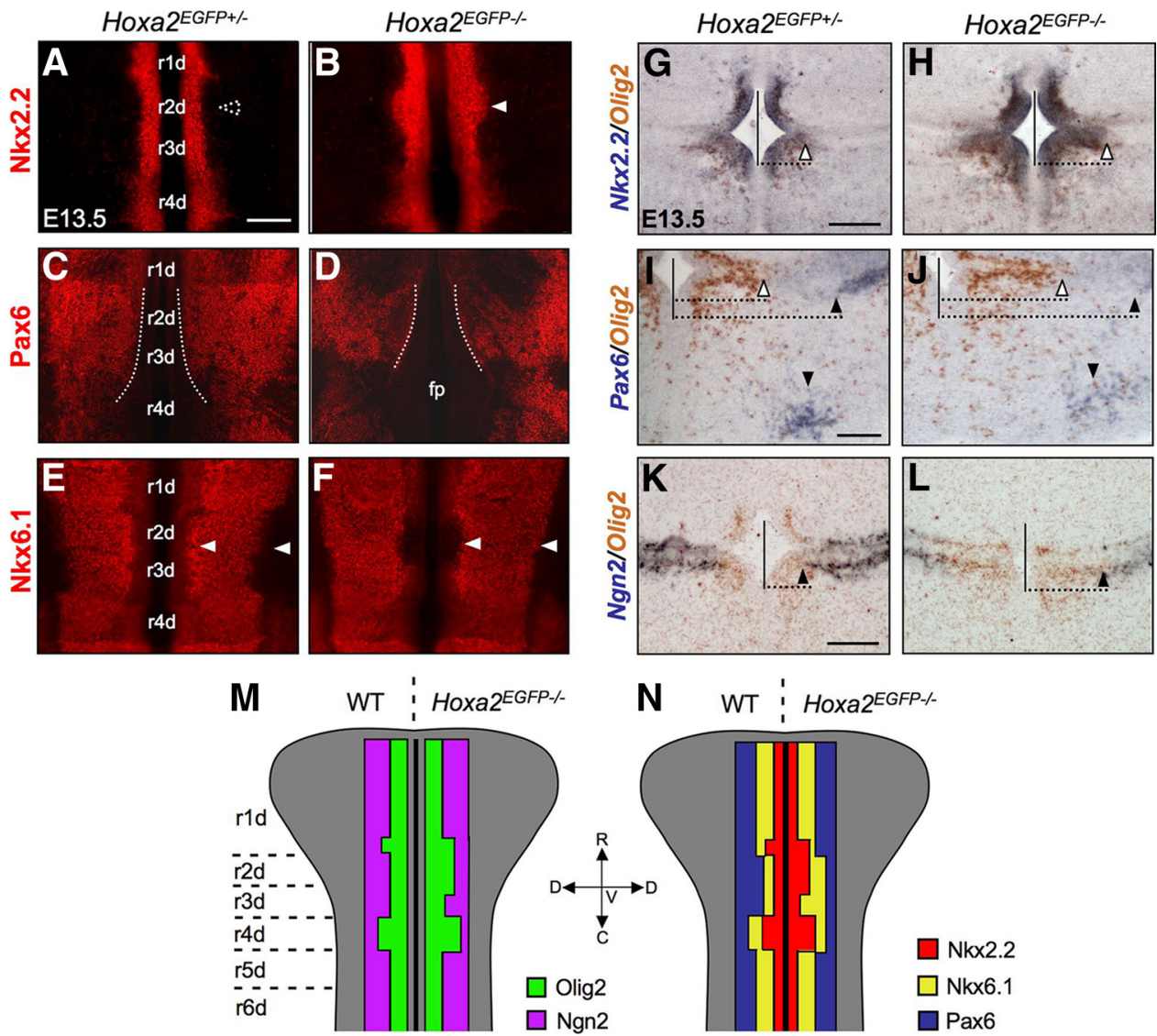

Figure 5. Rhombomere-specific alterations of bHLH and HD transcription factors after Hoxa2 deletion. $\boldsymbol{A}-\boldsymbol{F}$, Hindbrain flat-mounts from Hoxa2 ${ }^{E G F+/-}$ and Hoxa2 ${ }^{E G F P-/-}$ E13.5 embryos immunolabeled with anti-Nkx2.2 $(\boldsymbol{A}, \boldsymbol{B}), \operatorname{Pax} 6(\boldsymbol{C}, \boldsymbol{D})$, or Nkx6.1 $(\boldsymbol{E}, \boldsymbol{F})$ antibodies. In Hoxa $2^{\mathrm{EGFP}-1-}$ mutants, the Nkx2.2 ${ }^{+}$domain expands more dorsally in r2d $\left(\boldsymbol{B}\right.$, arrowheads), the Pax6 ${ }^{+}$domain extends less ventrally ( $\boldsymbol{D}$, dotted line), and the Nkx6.1 ${ }^{+}$domain shows a ventral downregulation and a dorsal expansion in r2d-r3d $(\boldsymbol{F}$, white arrowheads), compared with controls $(\boldsymbol{A}, \boldsymbol{C}, \boldsymbol{E})$. $\boldsymbol{G}-\boldsymbol{L}$, Double in situ hybridizations performed on coronal sections from Hoxa2 $2^{E G F P+/-}$ and Hoxa2 ${ }^{E G F P-/-}$ E13.5 embryos at the r2d-r4d level, labeled for Olig2 (brown) and either Nkx2.2 (G, $\left.\boldsymbol{H}\right)$, Pax6 (I, J), or Ngn2 ( $\boldsymbol{K}, \boldsymbol{L})$ (blue) probes. In Hoxa2-deficient mice, Olig2 ( $\mathbf{G}-\mathbf{J}$, white arrowheads) and $N k \times 2.2(\mathbf{G}, \boldsymbol{H}$, white arrowheads) expression domains are expanded dorsally in the ventral plate of $\mathrm{r} 2 \mathrm{~d}-\mathrm{r} 4 \mathrm{~d}$, whereas Pax $6(\boldsymbol{I}, \boldsymbol{J}$, black arrowheads) and $\operatorname{Ngn} 2(\boldsymbol{K}, \boldsymbol{L}$, black arrowheads) are ventrally downregulated. $\boldsymbol{M}, \boldsymbol{N}$, Schematic representations of flat-mounted E13.5 hindbrains indicating alterations of bHLH $(M)$ and HD $(\boldsymbol{N})$ transcription factor expression in Hoxa2-deficient mice. $r(n)$ d, Rhombomere-derived domain; $f$, floor plate; $R$, rostral; $C$, caudal; $V$, ventral; $D$, dorsal. $n=3$ animals of each type. Scale bars: $\boldsymbol{A}-\boldsymbol{F}, 200 \mu \mathrm{m} ; \boldsymbol{G}-\boldsymbol{L}, 100 \mu \mathrm{m}$.

To assess the temporal requirement of Hoxa2, we next tested whether increased oligodendrogenesis could be still induced by deleting Hoxa2 after establishment of RC and DV rhombomere patterning, though before the onset of oligodendrogenesis. A Hoxa $2^{\text {flox }}$ allele (Ren et al., 2002) was mated with a Tx-inducible CMV-Bactin-Cre-ERT2 line (Santagati et al., 2005). As hindbrain oligodendrogenesis starts at $\sim$ E12.5, and it takes $\sim 36-48 \mathrm{~h}$ after $\mathrm{Tx}$ treatment to induce efficient CreERT2-mediated excision, we administered Tx by oral gavage to E10.5 pregnant CMV-Cre-ERT2;Hoxa flox/flox $^{\text {homozy- }}$ gous mutant females (see Materials and Methods). At E13.5, Tx-induced CMV-Cre-ERT2;Hoxa2 flox/flox mutants showed an increased number of Olig2 ${ }^{+}$and PDGFR $\alpha^{+}$OPCs in the basal plate of r3d-r4d, compared with control Tx-treated Hoxa $2^{\text {flox fllox }}$ embryos, similar to Hoxa $2^{E G F P-1-}$-deficient mice (Fig. $4 I-N$ ). This phenotype was due to an increased cell proliferation in the ventricular zone, as shown by the greater number of $\mathrm{PH}^{+}{ }^{+}$cells compared with controls (Fig. 4O,P; mean number of $\mathrm{PH} 3^{+}$cells per area $\left(\mathrm{mm}^{2}\right) \pm$ SEM: Hoxa2 flox/flox, $30.6 \pm 1.6 ; C M V$-CreERT2; Hoxa2 $2^{\text {flox/flox }}, 42.4 \pm 1.9 ; p<0.0001$, Student's $t$ test, $n=$ 4). In r2d-r3d territories, $\mathrm{PH}^{+}$cells located in the ventral and lateral plates displayed an increase of $\mathrm{PH} 3^{+} / \mathrm{PDGFR} \alpha^{+}$OPCs (percentage of $\mathrm{PH} 3^{+} / \mathrm{PDGFR} \alpha^{+}$cells/total PDGFR $\alpha^{+}$cells \pm SEM: Hoxa $2^{\text {flox/flox }}, 1.2 \pm 0.7$; CMV-Cre-ERT2; Hoxa2 $2^{\text {flox/flox }}$,
$4.2 \pm 0.2 ; p=0.0034$; Student's $t$ test, $n=4$ ). Immunostaining for cleaved caspase- 3 showed no differences in OPC survival between mutants and control mice (no caspase- $3^{+}$cells detected in the r2d-r3d domain of controls and Hoxa2 mutants). Thus, Hoxa2 function is required at least until the onset of oligodendrogenesis.

In summary, our functional gain-of-function and loss-offunction data provide converging evidence that Hoxa2 is normally required to spatially and quantitatively restrict the generation of ventral $\mathrm{Olig}^{+}$progenitors in the rostral hindbrain.

\section{Hoxb2 promotes hindbrain oligodendrogenesis}

Previous studies established that Hoxb2 has an important role in neuronal patterning in the ventral hindbrain (Barrow and Capecchi, 1996; Davenne et al., 1999; Pattyn et al., 2003). Indeed, in the Nkx2.2 $2^{+}$domain of ventral r4d, Hoxb2 contributes to facial motor neuron generation by maintaining high expression levels of the paired HD factor Phox $2 b$, which, in turn, suppresses serotonergic (5HT) fate (Pattyn et al., 2003). To evaluate the role of Hoxb2 in ventral oligodendrogenesis, we examined the oligodendroglial phenotype of Hoxb2 loss-offunction mutants, Hoxb2 $2^{\text {del/del }}$ (see Materials and Methods). At E13.5, Hoxb2 ${ }^{\text {del/del }}$ hindbrain flat-mounts displayed a reduced 

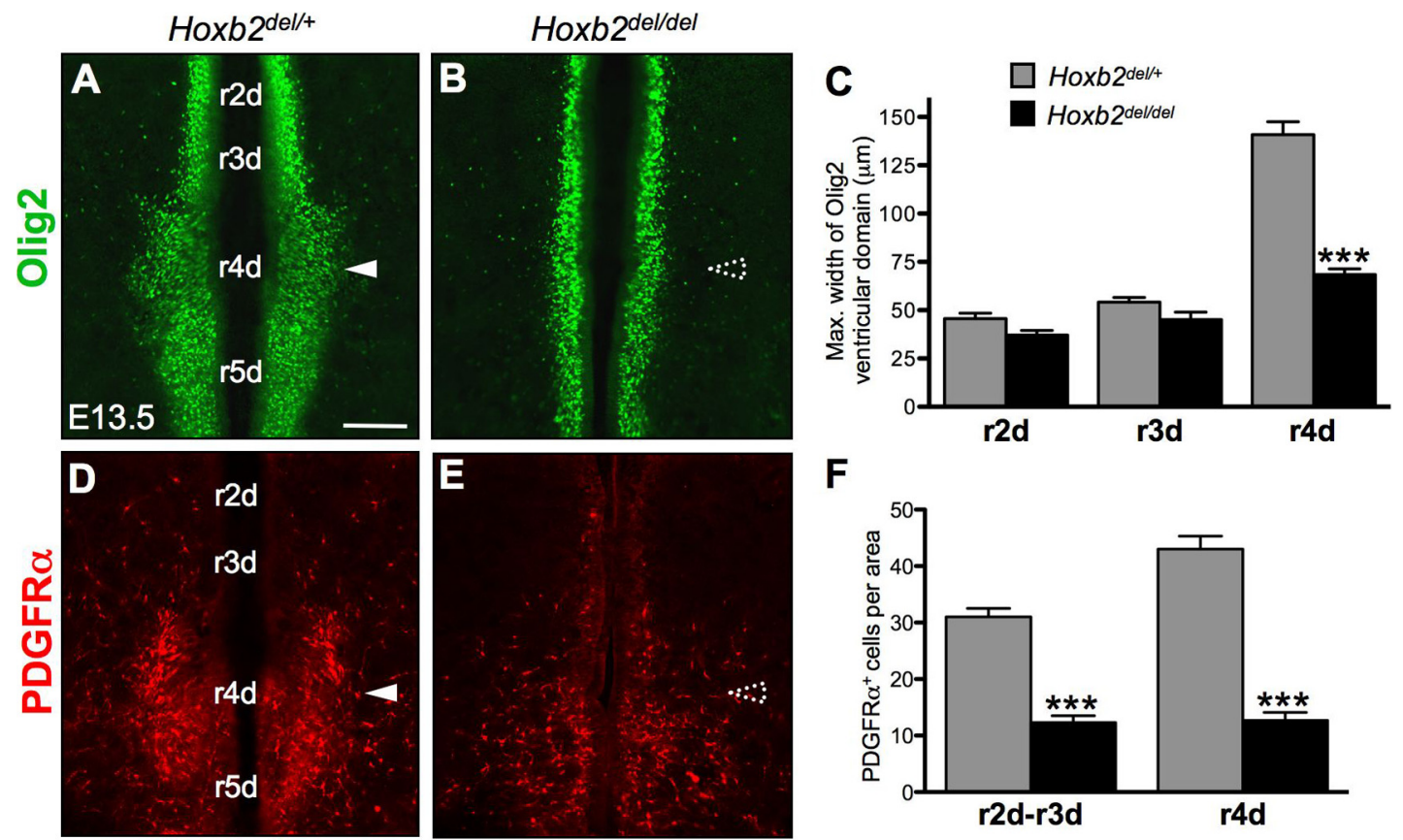

$\mathbf{F}$
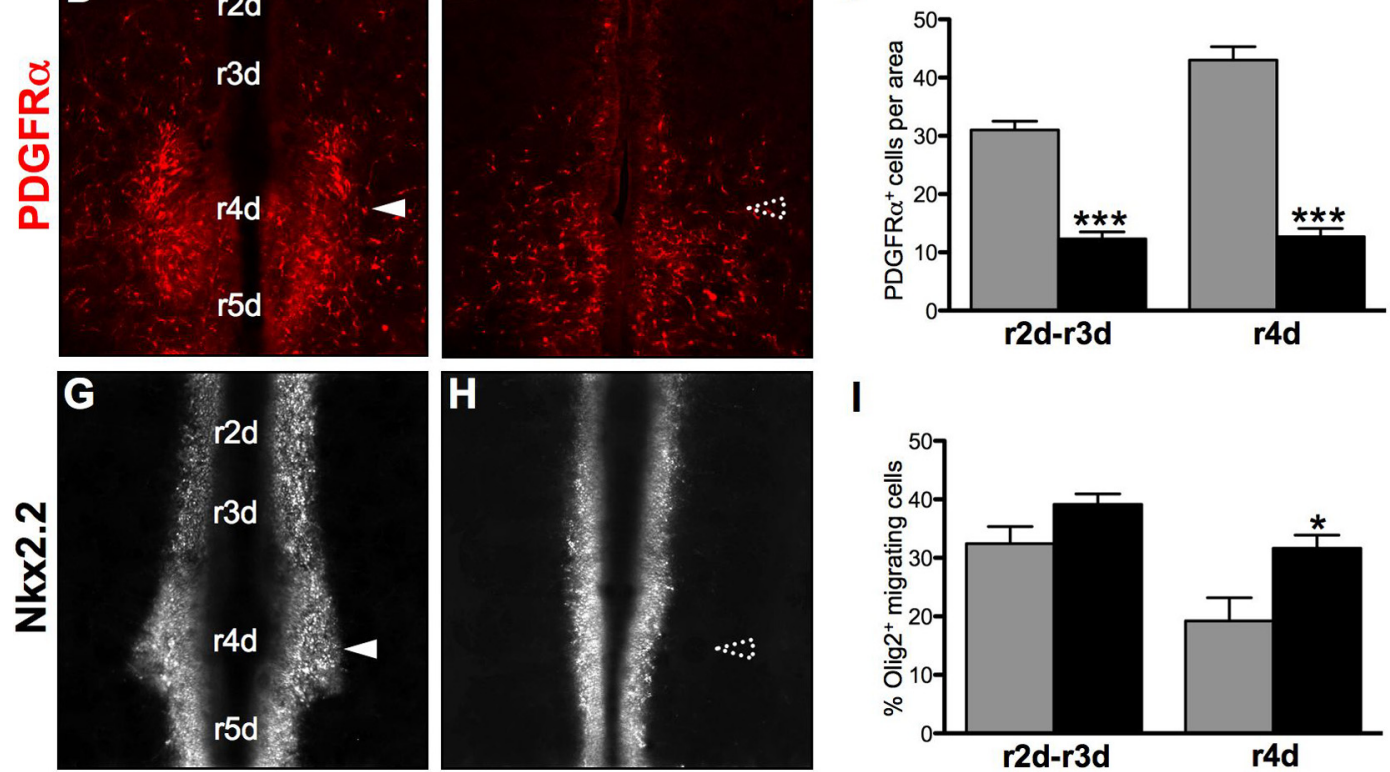

\section{I}
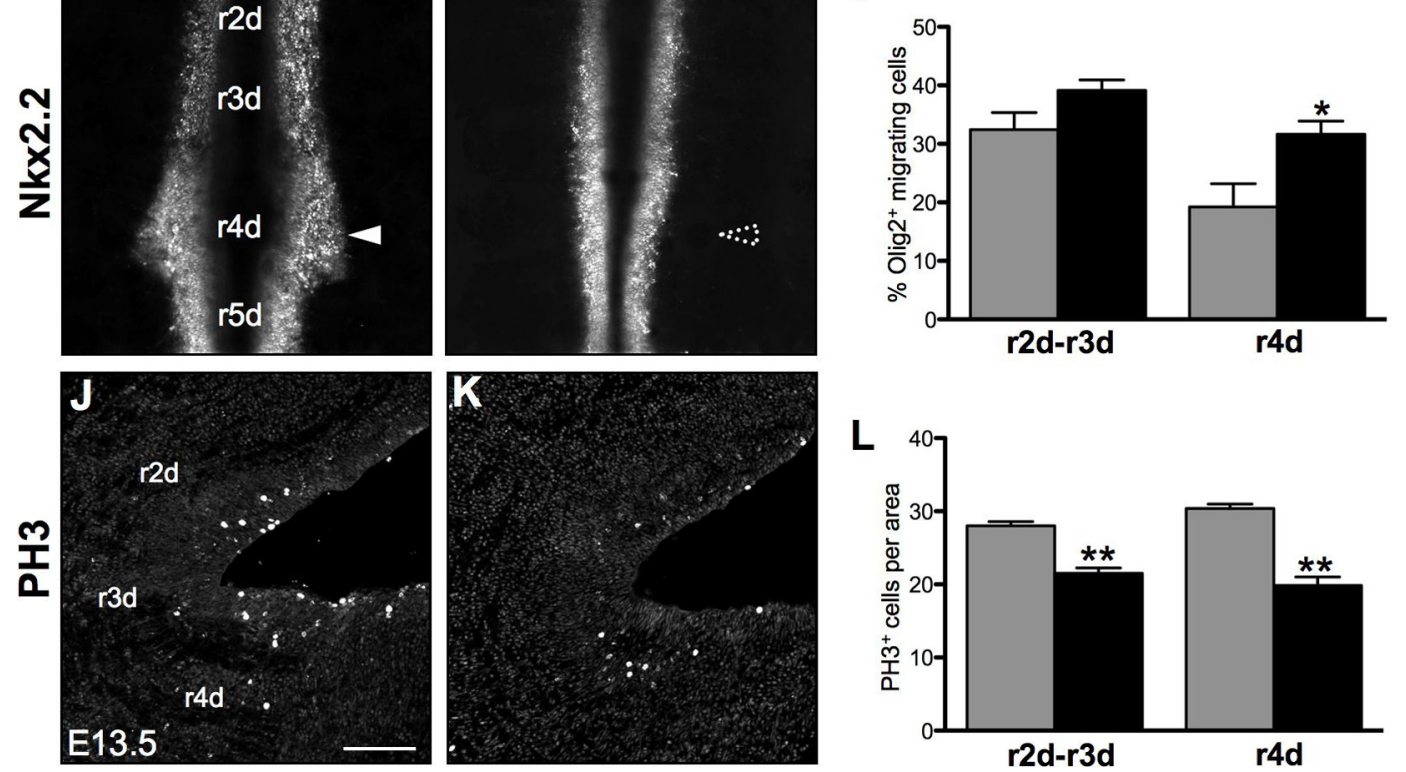

Figure 6. Hoxb2 deletion decreases oligodendrogenesis. $A-I$, Flat-mounted hindbrains from $H_{0 x b 2} 2^{d e l /+}(\boldsymbol{A}, \boldsymbol{D}, \mathbf{G})$ and $H_{0 x b 2} 2^{\text {del/del }}(\boldsymbol{B}, \boldsymbol{E}, \boldsymbol{H})$ embryos at E13.5, analyzed after immunolabeling with anti-0lig2 (green), anti-PDGFR $\alpha$ (red), and anti-Nkx2.2 (white) antibodies. Hoxb2 deletion results in a reduction of the dorsoventral extension of Olig2 $(\boldsymbol{A}-\boldsymbol{C})$ and Nkx2.2 (G, $\boldsymbol{H})$ ventricular domains in r4d, as well as in a decreased number of PDGFR $\alpha^{+}$cells $(\boldsymbol{D}-\boldsymbol{F})$ in $\mathrm{r2d}$-r4d. Hoxb2-null embryos also show a higher percentage of 0 lig $2^{+}$migrating cells in r4d, compared with control animals (I). $J-L$, Sagittal sections from Hoxb2 $2^{\text {del/ }+}(\boldsymbol{J})$ and Hoxb2 ${ }^{\text {del/del }}(\boldsymbol{K})$ mice at E13.5, labeled for PH3. Hoxb2 $2^{\text {del/del }}$ embryos display a reduced number of proliferating cells in $\mathrm{r} 2 \mathrm{~d}-\mathrm{r} 4 \mathrm{~d}$. $\mathrm{r}(n) \mathrm{d}$, rhombomerederived domain. $C: r 4 d, p<0.0001 ; F:$ r $2 \mathrm{~d}-\mathrm{r} 3 \mathrm{~d}, p=0.0007 ; \mathrm{r} 4 \mathrm{~d}, p=0.0004 ; \mathrm{I}: \mathrm{r} 4 \mathrm{~d}, p=0.0256 ; \boldsymbol{L}: \mathrm{r} 2 \mathrm{~d}-\mathrm{r} 3 \mathrm{~d}, p=0.0025 ; \mathrm{r} 4 \mathrm{~d}, p=0.0013 ; n=4$ animals of each type. Area, $1 \mathrm{~mm}{ }^{2}$. Scale bars, $100 \mu \mathrm{m} .{ }^{*} p<0.05 ;{ }^{* *} p<0.01 ;{ }^{* * *} p<0.001$.

Olig2 ${ }^{+}$domain in r4d (Fig. $6 A-C$ ) and a decreased number of ventral PDGFR $\alpha^{+}$OPCs (Fig. 6D-F), compared with control embryos. The Nkx2.2 expression domain, which is dorsally enlarged at the level of $\mathrm{r} 4 \mathrm{~d}$ in wild-type embryos, compared with r2d-r3d, was also reduced in size (Fig. 6G,H). Unlike Hoxa2, Hoxb2 appears to positively regulate cell proliferation in the prepontine and pontine regions ( $\mathrm{r} 3 \mathrm{~d}-\mathrm{r} 4 \mathrm{~d})$, as shown by the reduced number of $\mathrm{PH} 3{ }^{+}$cells present in Hoxb2 $2^{\text {del/del }}$ mutants, compared with wild-type littermates (Fig. $6 J-L$ ). Hoxb2 might also regulate OPC migration, since we observed an increased percentage of migrating Olig ${ }^{+}$cells in the $\mathrm{r} 4 \mathrm{~d}$ of Hoxb2-deficient mice (Fig.
6I). At E18.5, we found no apparent differences in the number of PDGFR $\alpha^{+}$OPCs and mature $\mathrm{CNP}^{+}$oligodendrocytes in the rostral hindbrain between Hoxb2 $2^{\text {del/del }}$ mutants and controls (data not shown). Thus, the decrease in the number of OPCs formed at E13.5 has been compensated and did not result in a reduced population of mature oligodendrocytes.

In summary, the lack of Hoxb2 results in a phenotype opposite to that of Hoxa2 inactivation. Namely, unlike Hoxa2, Hoxb2 promotes expansion of OPCs, especially in $\mathrm{r} 4 \mathrm{~d}$, where it also promotes extended facial motor neuron generation (Pattyn et al., 2003). 

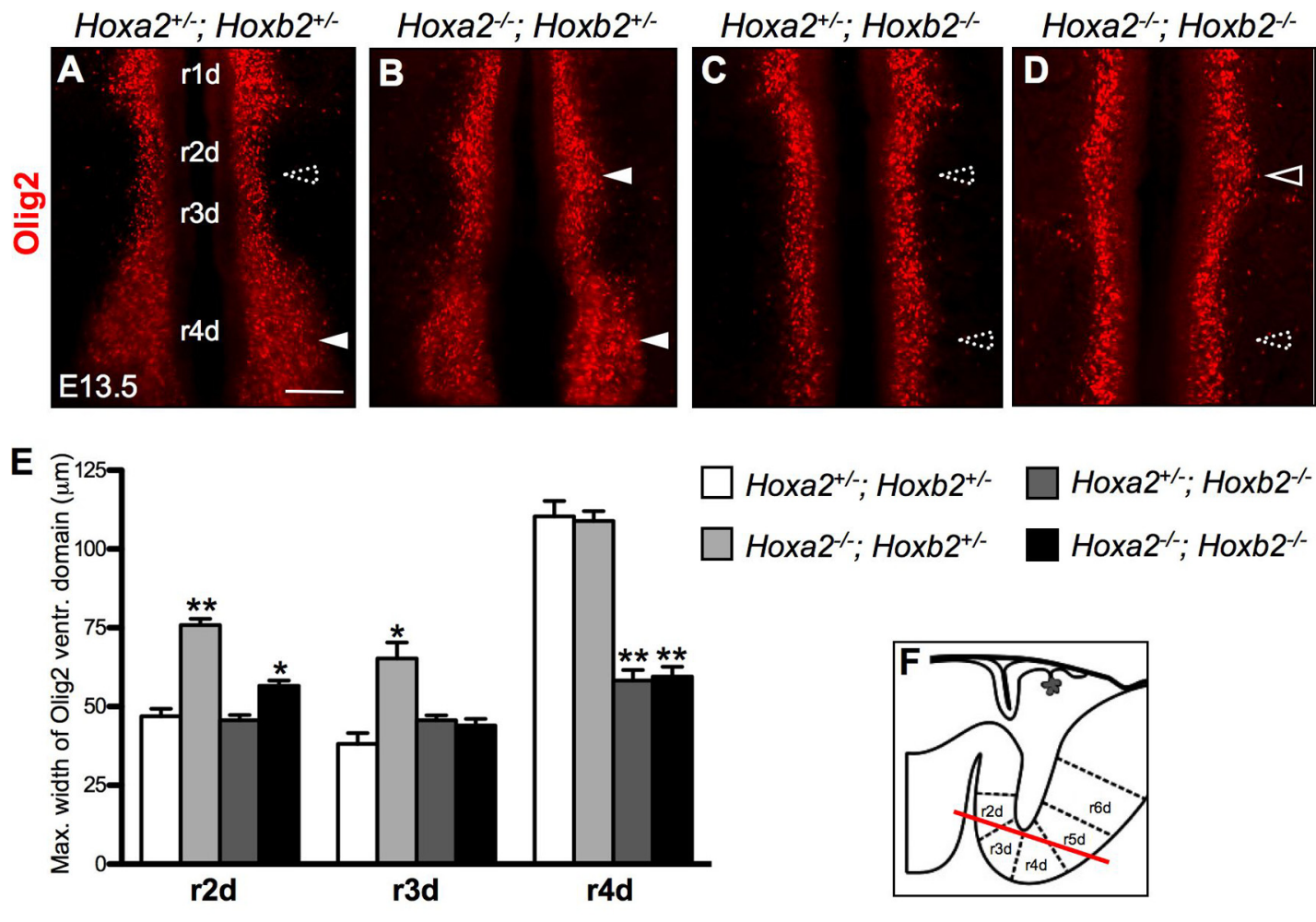

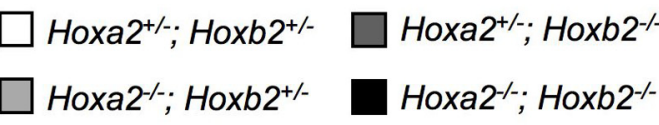
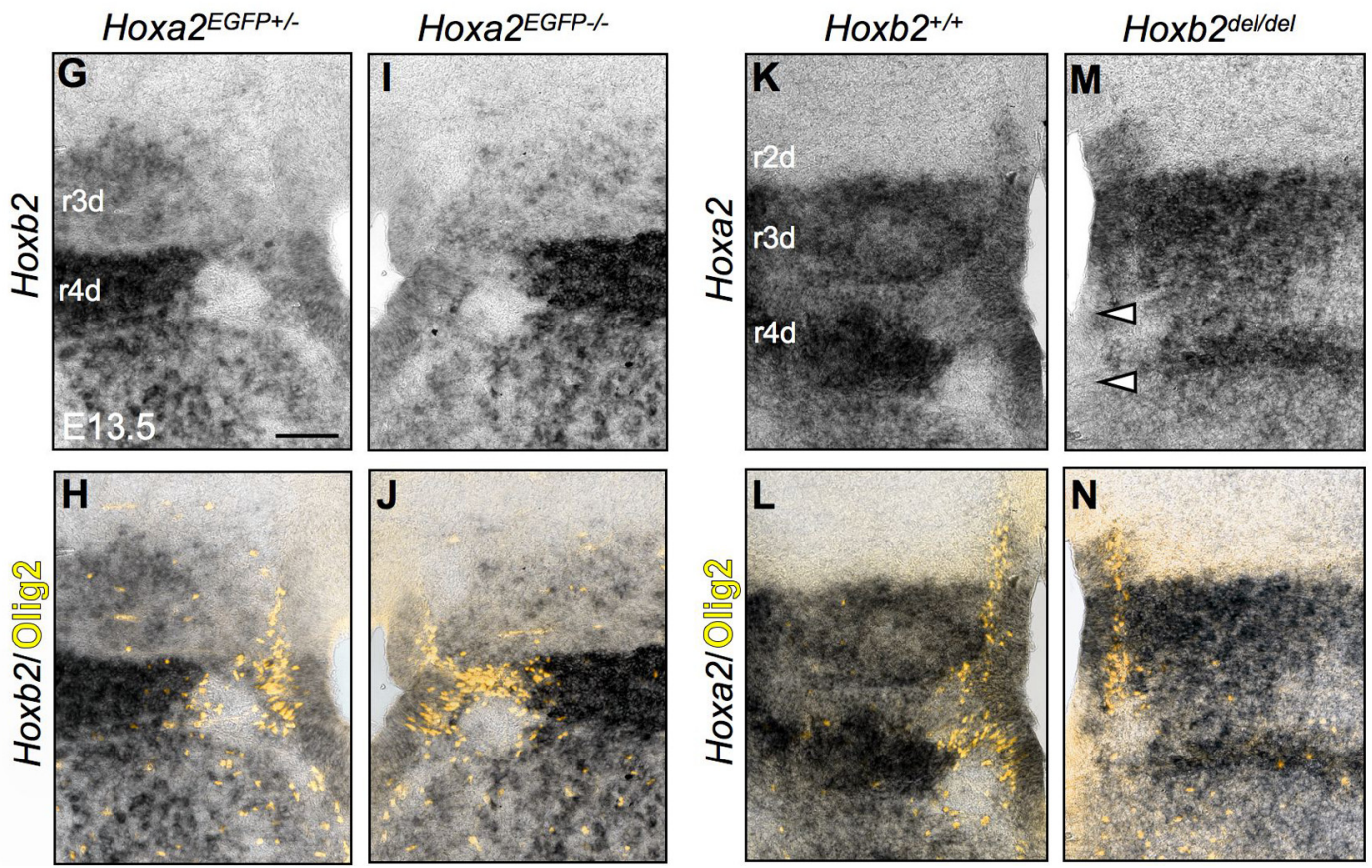

Figure 7. Cross-regulatory interaction between Hoxa2 and Hoxb2 in hindbrain oligodendrogenesis. $\boldsymbol{A}-\boldsymbol{E}$, Hindbrain flat-mounts from Hoxa2 $2^{+/-} / \mathrm{Hoxb2}^{+/-}(\boldsymbol{A}), \mathrm{Hoxa2}^{-/-} /$ Hoxb2 $2^{+/-}(\boldsymbol{B}), \mathrm{Hoxa2}^{+/-} / \mathrm{Hoxb2}^{-1-}(\boldsymbol{C})$, and Hoxa2 $2^{-/-} / \mathrm{Hoxb2}^{-/-}(\boldsymbol{D})$ E13.5 embryos analyzed after immunolabeling with anti-0lig2 antibody. The dorsoventral extension of 0 lig2 ${ }^{+}$ventricular domain in each rhombomere is indicated in $\boldsymbol{E}$. Compared with double heterozygous control animals $(\boldsymbol{A})$, Hoxa2 $^{-/-} /$Hoxb2 $^{-/-}$embryos $(\boldsymbol{D})$ show $(1)$ an enlarged 0 lig2 ${ }^{+}$ventricular domain in $\mathrm{r} 2 \mathrm{~d}$, but not in $\mathrm{r} 3 \mathrm{~d}$, where this effect is compensated by the loss of Hoxb2; (2) a reduced Olig2 ${ }^{+}$ventricular domain in $\mathrm{r}_{4}$, like in $\mathrm{Hoxa2}^{+/-} / \mathrm{Hoxb2}^{-\prime-}$ (C) or Hoxb2 ${ }^{-1-}$ mutants, independently of the loss of Hoxa2, indicating that Hoxb2 dominates Hoxa2 for the control of Olig2 expression. G-N, In situ hybridizations for Hoxb2 and Hoxa2 followed by Olig2 immunolabeling, performed on coronal sections from $\operatorname{Hoxa}_{2}{ }^{E G F P}(\boldsymbol{G}-\boldsymbol{J})$ and $\operatorname{Hoxb2}^{\text {del }}(\boldsymbol{K}-\boldsymbol{N})$ E13.5 mutants, respectively. Sections are localized as indicated in $\boldsymbol{F}$. Hoxb2 expression pattern was similar between $H o x a 2^{E G F P-1-}$ mutants and Hoxa2 ${ }^{\text {EGFP+/- }}$ controls $(\boldsymbol{G}, \boldsymbol{I})$. In contrast, Hoxa2 expression in the ventricular 0 lig2 ${ }^{+}$domain of $\mathrm{r} 4 \mathrm{~d}$ was

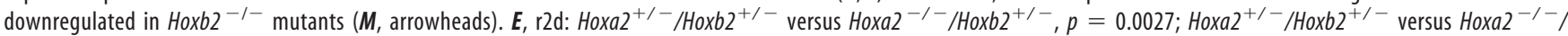

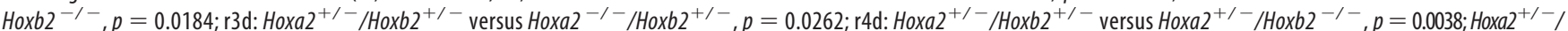
Hoxb2 $^{+/-}$versus Hoxa2 ${ }^{-\prime-} /$ Hoxb2 $^{-\prime-}, p=0.0035 ; n=3$ animals of each type. Scale bars, $100 \mu \mathrm{m} .{ }^{*} p<0.05 ; * * 00.01{ }^{* * *} p<0.001$. 


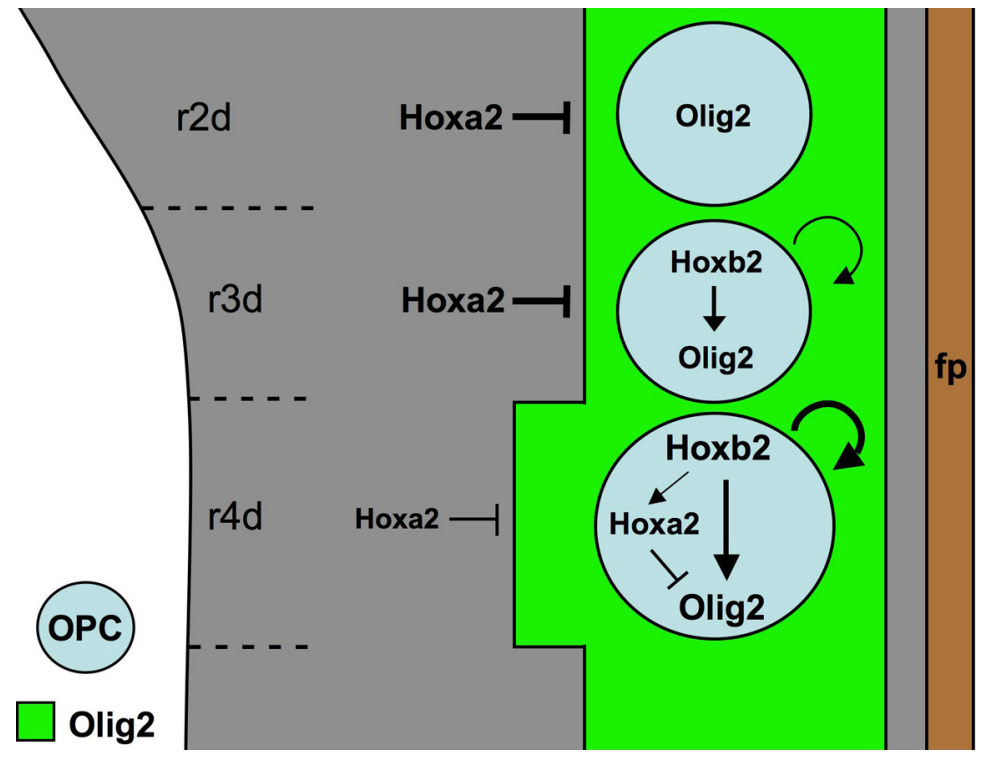

Figure 8. Working model of Hox PG2 action in oligodendrogenesis of rostral hindbrain. Hoxa2 and Hoxb2 have opposing effects on hindbrain oligodendrogenesis. Hoxa2 acts predominantly in the environment of Olig2 progenitors, especially in the Pax6 domain, where it represses Olig2 expression and limits the dorsal extension and the size of Olig2 progenitor domain. This effect is prominent in the $\mathrm{r} 2 \mathrm{~d}-\mathrm{r} 3 \mathrm{~d}$ domain. Hoxb2 promotes oligodendrogenesis and increases proliferation of 0 lig $2^{+}$progenitors and OPCs in the $\mathrm{r} 3 \mathrm{~d}-\mathrm{r} 4 \mathrm{~d}$ domain. This effect is especially robust in ventral $r 4 \mathrm{~d}$, where Hoxb2 controls Hoxa2 expression in the progenitor domain. $r(n)$ d, rhombomere-derived domain; fp, floor plate.

\section{Cross-regulatory interaction between Hoxa2 and Hoxb2 in hindbrain oligodendrocyte patterning}

The phenotypes of single Hoxa2 and Hoxb2 mutants indicate opposing roles for Hoxb2 and Hoxa2 in hindbrain oligodendrogenesis, suggesting that a net balance between Hoxa2 and Hoxb2 expression levels in the Olig2 ${ }^{+}$domain may modulate the number of OPCs generated in each rhombomere posterior to $\mathrm{r} 1$. To test this hypothesis, we analyzed the pattern of Olig $2^{+}$progenitors and PDGFR $\alpha^{+}$ OPCs in compound Hoxa2/Hoxb2 mutants and their littermates at stage E13.5 (Fig. 7A-E). In r2d, where Hoxa2, but not Hoxb2, is expressed, Hoxa $2^{-/-} /$Hoxb $2^{-/-}$mutants showed, as expected, a similar dorsal expansion of the Olig $2^{+}$domain as in single Hoxa $2^{-1-}$ mutants. Interestingly, in $\mathrm{r} 3 \mathrm{~d}$, the loss of Hoxb2 in double Hoxa $2^{-/-} / H_{0} \times 2^{-/-}$homozygotes was sufficient to prevent the increased oligodendrogenesis displayed by single Hoxa2 ${ }^{-1-}$ mutants. Thus, the Olig2 expression pattern in $\mathrm{r} 3 \mathrm{~d}$ suggests that the promoting effect of Hoxb2 on oligodendrogenesis is dominant upon the inhibitory action of Hoxa2. This was further supported by the finding that in $\mathrm{r} 4 \mathrm{~d}$ of Hoxa $2^{-/-} / \mathrm{Hoxb}^{-/-}$mutants, the reduction of the Olig2 ${ }^{+}$ventral domain (Fig. 7D) was similar to that of $\mathrm{Hoxa2}^{+/-} / \mathrm{Hoxb2}^{-/-}$ (Fig. 7C) and single Hoxb2 $2^{-/-}$mutants (Fig. 6B), while single Hoxa $2^{-1-}$ mutants displayed a twofold increase of Olig ${ }^{+}$cells in this domain (Fig. 4C). The Olig2 expression pattern in r4d confirms that Hoxb2 antagonizes and dominates Hoxa2 in the regulation of rhombomere-specific oligodendrogenesis.

To determine whether Hoxa2 and Hoxb2 each regulates each other's expression, we examined the hindbrain expression pattern of Hoxa2 in Hoxb2 mutants and, reciprocally, of Hoxb2 in Hoxa2-deficient embryos (Fig. $7 F-N$ ). The Hoxb2 expression pattern was not changed in Hoxa $2^{E G F P-/-} \mathrm{mu}-$ tants, compared with Hoxa2 $2^{E G F P+/-}$ controls (Fig. $7 G-J$ ). In contrast, in Hoxb2 $2^{-1-}$ mutants, Hoxa2 was significantly downregulated in the ventricular Olig $2^{+} / \mathrm{Nkx} 2.2^{+}$progenitor domain of r4d (Fig. $7 K-N$, arrowheads). This is in agreement with a direct regulatory role for Hoxb2 in maintaining Hoxa2 expression levels in r4 (Lampe et al., 2008) and explains the similar oligodendrocyte phenotypes of single Hoxb2 $2^{-1-}$ and compound Hoxa $2^{-/-} /$Hoxb2 $2^{-1-}$ mutants in the ventral r4d domain. Therefore, Hoxa2 and Hoxb2 likely act together in ventral oligodendrocyte progenitors, at least in $\mathrm{r} 4 \mathrm{~d}$, exerting opposite modulatory effects on the molecular processes regulating OPC specification and proliferation.

\section{Discussion}

In this study, we found that Hox PG2 genes have opposing roles in the regulation of oligodendrocyte generation and patterning in the rostral hindbrain. In the spinal cord, Hox homeoproteins are expressed by oligodendroglial cells (Nicolay et al., 2004a,b; Booth et al., 2007), raising the possibility that they may confer RC identity to oligodendrocytes. However, in the spinal cord of Hoxa2-deficient mice, no anomalies were detected in the number, migration, and differentiation of OPCs (Nicolay et al., 2004b). Nonetheless, many Hox genes are coexpressed at the level of the spinal cord, thus providing the potential for functional redundancy that may mask the involvement of individual Hox factors. To overcome the redundancy pitfall and investigate the possible involvement of Hox PG2 factors in oligodendrogenesis, we focused on the rostral hindbrain where Hoxa 2 and Hoxb2 perform their main functional role. Indeed, we provide evidence that Hoxa2 and Olig2 expression levels are inversely correlated in progenitor cells, and that Hoxa 2 might be involved in restricting the ventral domain of oligodendrocyte specification. From E12.5 to E14.5, ventral oligodendrogenesis is induced in prepontine and pontine territories in progenitors expressing low levels of Hoxa2. In mice conditionally overexpressing Hoxa 2 in Olig2 ${ }^{+}$progenitors, the size of the ventral Olig2 domain is reduced, especially in $\mathrm{r} 2 \mathrm{~d}-\mathrm{r} 3 \mathrm{~d}$ territories. The inhibition of oligodendrogenesis induced by Hoxa2-overexpression may occur independently of environmental cues, as it is not only evident in the hindbrain but also, more generally, in other brain regions, such as the ventral forebrain. In Hoxa2-deficient mice, there is a dorsal expansion of the ventral Olig2 ${ }^{+} / \mathrm{Nkx} 2.2^{+}$domain resulting in increased oligodendrogenesis. This is in part due to the loss of Hoxa2 expression at the ventral border of the abutting $\mathrm{Pax}^{+}$ventricular domain, where Hoxa2 is normally highly expressed, and to ectopic recruitment of Olig2 ${ }^{+}$progenitors. Like Hoxa2, Hoxb2 is expressed in the ventral plate, but, unlike Hoxa2, it promotes Olig2 expression, as indicated by the narrowing of the Olig2 domain in the r4d ventral plate of Hoxb2deficient mice and double Hoxa2 $2^{-/-} / \mathrm{Hoxb2}^{-/-}$mutants. The coexpression of Hoxa2 and Hoxb2 transcripts in the ventral $\mathrm{Nkx} 2.2^{+}$ventricular domain and the downregulation of Hoxa2 expression in the $\mathrm{r} 4 \mathrm{~d}$ ventral ventricular domain of Hoxb2 $2^{-1-}$ mutants, suggest a feedforward cross-regulatory inhibitory mechanism between Hoxb2 and Hoxa2 to regulate the number and the local production of oligodendrocytes in ventral progenitor cells of the rostral hindbrain.

Figure 8 proposes a schematic model to explain how Hox PG2 genes can regulate rostral hindbrain oligodendrogenesis. High Hoxa2 expression levels are required to maintain the ventral bor- 
der of Pax6 expression, where it contributes to repress Olig2 activation in ventricular progenitors. Pax6 may directly bind to the Olig2 promoter and repress Olig2 expression, as recently reported in stem/progenitor cells (Jang and Goldman, 2011). Moreover, Olig2 ${ }^{+}$progenitors may be specified at the dorsal edge of the $N k \times 2.2^{+}$domain at a developmental stage when Hoxa2 expression levels are declining. This is suggested by the observation that forced maintenance of high Hoxa2 expression levels in Olig2 ${ }^{+}$ cells, as in Olig2-tva-Cre;ROSA ${ }^{(\text {lox-stop-lox }) H o x a 2}$ mice, inhibits oligodendrogenesis. Regarding Hoxb2, our data show that it promotes progenitor cell proliferation in the ventroalar plate and acts in $\mathrm{Olig}^{+}$ventral progenitors to increase oligodendrogenesis, likely by counteracting Hoxa2-mediated inhibition in r3d and $\mathrm{r} 4 \mathrm{~d}$. However, it is noteworthy that in the ventral $\mathrm{r} 4 \mathrm{~d}$ $N k \times 2.2^{+}$domain Hoxb2 is also involved in the maintenance of high Hoxa2 expression levels, which, in turn, inhibit the generation of $\mathrm{Olig}^{+}$progenitors. Such a transcriptional crossregulation of Hoxb2 on Hoxa2 may be direct, since a Hoxa2 r4-specific enhancer regulated by Hoxb1 and/or Hoxb2 has been previously identified (Tümpel et al., 2007; Lampe et al., 2008). Concerning Hoxb2 regulation of Olig2 expression, it could be direct, by binding onto Olig2 promoter, or indirect, by modulating the expression of effectors of signaling molecules regulating Olig2 expression, including those induced by $\mathrm{SHH}$.

The alterations of DV patterning observed in the rostral hindbrain of Hox PG2 mutants suggest that Hox PG2 genes regulate cell fate choices within several progenitor domains along the DV axis (Davenne et al., 1999). The $N k \times 2.2^{+}$progenitor domain of $\mathrm{r} 2 \mathrm{~d}$ and $\mathrm{r} 3 \mathrm{~d}$, but not $\mathrm{r} 4 \mathrm{~d}$, generates the serotonergic lineage before the onset of oligodendrogenesis (Pattyn et al., 2003). We found that the number and distribution of $5 \mathrm{HT}^{+}$cells was not modified in Hoxa2-deficient or in Hoxa2-overexpressing mice, compared with controls, suggesting that OPCs are not produced at the expense of serotonergic progenitors and that Hoxa2 does not regulate serotonergic versus oligodendroglial cell fate balance in Nkx2.2-expressing progenitors (data not shown). Dorsally to the Nkx2.2 $2^{+} \mathrm{Olig}^{+}$ventral domain, the Pax6 ventricular domain includes a ventral subset of progenitors committed to generate astroglial cells (Hochstim et al., 2008). In Hoxa2-deficient embryos, a normal number of glial cells expressing Sox9 form in the rostral hindbrain (data not shown). Since Sox9 is a common marker for immature oligodendroglial and astroglial cells (Stolt et al., 2003), this suggests that fewer astrocytes and more OPCs are produced compared with wild-type mice. The excess of OPCs generated in the ventral plate of these mutants may be produced at the expense of astrocytes derived from the reduced Pax6 domain. In contrast, the gain of ventral oligodendrogenesis in Hoxa $2^{\text {EGFP-1- }}$ embryos is not associated with a loss or a reduction of dorsal oligodendrogenesis, which later derives from the Pax3/Pax7/Gsh1 ventricular domain (Vallstedt et al., 2005), as no alterations of Pax3 and Pax7 expression patterns were detected in the hindbrain of these mutants.

The observations reported here indicate that rostral hindbrain oligodendrogenesis develops in the ventral plate with a defined spatiotemporal pattern involving segment-specific subpopulations of oligodendroglial progenitors of different size and distribution. Hoxa2 and Hoxb2 appear to contribute to the dorsoventral patterning of ventricular progenitors and to regulate spatially restricted proliferation of progenitor and precursor cells in the ventroalar plate. Although additional effects on the migration of OPCs cannot be ruled out, especially for Hoxb2 in r4d, Hox PG2 genes appear to be mainly required at an early stage of regional OPC generation from ventral progenitor cells. Moreover, Hoxa2 and Hoxb2 do not appar- ently contribute to regulate oligodendrocyte differentiation, since neither Hoxa2 nor Hoxb2 mutations altered the number of $\mathrm{CNP}^{+}$oligodendrocytes in the rostral hindbrain. The action of Hox PG2 genes is temporally restricted and the number of OPCs produced at the onset of oligodendrogenesis in Hoxa2 or Hoxb2 mutants is rapidly normalized before birth. In Hoxa2 gain-offunction and Hoxb2-deficient mutants, the reduced number of ventricular progenitors and early born OPCs are likely compensated by an additional cell cycle of OPCs before they differentiate. In Hoxa2 loss-of-function mutants, the elimination of extra numerous OPCs born at E13.5 probably result from the competition between OPCs to use the limited amount of PDGF-A available in the environment, since PDGF-A-driven cell survival controls override proliferation for determining the final number and distribution of mature oligodendrocytes (Calver et al., 1998).

Hox PG2 genes participate in rostral hindbrain oligodendrogenesis, but may also regulate OPC production and behavior in more caudal regions of the neural tube, where such genes are expressed. It is very likely that, in addition to Hoxb2, other Hox genes may modulate the repressing effect of Hoxa2 to control the ventral expression of Olig2 and the size of the ventral oligodendrogenic domain. A more complete picture of Hox gene function in oligodendroglial development would require global and inducible Hox deletion. Hox proteins require common Pbx cofactors to achieve their function (Moens and Selleri, 2006). Conditional deletion of $\mathrm{Pbx}$ (pre-B cell leukemia transcription) factors in OPCs may provide useful genetic models to better evaluate the importance of Hox regulation in brainstem and spinal cord oligodendrogenesis.

In patients with multiple sclerosis, not only is the distribution of demyelinating lesions extremely variable, but the capacity of remyelination varies depending on the lesioned territory. For instance, it has been reported that cortical lesions remyelinate much more efficiently than periventricular plaques (Patrikios et al., 2006; Albert et al., 2007). This local vulnerability of myelin raises the possibility that it could be related to regional populations of oligodendrocytes with different myelin vulnerabilities and/or repair abilities. Investigating the molecules conferring the regional identity of oligodendrocytes may thus have an important impact on therapeutic strategies aimed at favoring or enhancing myelin repair following white matter lesions at spatially restricted locations in the CNS. In this respect, it may be of particular interest to examine whether a differential expression of either HOXA2 or HOXB2 in multiple sclerosis lesions in the hindbrain may account for the different capacity of some lesions to repair or not, and whether manipulating HOX PG2 factors may contribute to increase myelin repair.

\section{References}

Albert M, Antel J, Brück W, Stadelmann C (2007) Extensive cortical remyelination in patients with chronic multiple sclerosis. Brain Pathol 17:129138. CrossRef Medline

Barrow JR, Capecchi MR (1996) Targeted disruption of the Hoxb-2 locus in mice interferes with expression of Hoxb-1 and Hoxb-4. Development 122:3817-3828. Medline

Booth J, Nicolay DJ, Doucette JR, Nazarali AJ (2007) Hoxd1 is expressed by oligodendroglial cells and binds to a region of the human myelin oligodendrocyte glycoprotein promoter in vitro. Cell Mol Neurobiol 27:641650. CrossRef Medline

Cai J, Qi Y, Hu X, Tan M, Liu Z, Zhang J, Li Q, Sander M, Qiu M (2005) Generation of oligodendrocyte precursor cells from mouse dorsal spinal cord independent of Nkx6 regulation and Shh signaling. Neuron 45:41-53. CrossRef Medline

Calver AR, Hall AC, Yu WP, Walsh FS, Heath JK, Betsholtz C, Richardson 
WD (1998) Oligodendrocyte population dynamics and the role of PDGF in vivo. Neuron 20:869-882. CrossRef Medline

Davenne M, Maconochie MK, Neun R, Pattyn A, Chambon P, Krumlauf R, Rijli FM (1999) Hoxa2 and Hoxb2 control dorsoventral patterns of neuronal development in the rostral hindbrain. Neuron 22:677-691. CrossRef Medline

Davies JE, Miller RH (2001) Local sonic hedgehog signaling regulates oligodendrocyte precursor appearance in multiple ventricular zone domains in the chick metencephalon. Dev Biol 233:513-525. CrossRef Medline

Di Lullo E, Haton C, Le Poupon C, Volovitch M, Joliot A, Thomas JL, Prochiantz A (2011) Paracrine Pax6 activity regulates oligodendrocyte precursor cell migration in the chick embryonic neural tube. Development 138: 4991-5001. CrossRef Medline

Dupé V, Davenne M, Brocard J, Doll é P, Mark M, Dierich A, Chambon P, Rijli FM (1997) In vivo functional analysis of the Hoxa-1 3' retinoic acid response element (3'RARE). Development 124:399-410. Medline

Dymecki SM (1996) Flp recombinase promotes site-specific DNA recombination in embryonic stem cells and transgenic mice. Proc Natl Acad Sci U S A 93:6191-6196. CrossRef Medline

Fogarty M, Richardson WD, Kessaris N (2005) A subset of oligodendrocytes generated from radial glia in the dorsal spinal cord. Development 132: 1951-1959. CrossRef Medline

Geisen MJ, Di Meglio T, Pasqualetti M, Ducret S, Brunet JF, Chedotal A, Rijli FM (2008) Hox paralog group 2 genes control the migration of mouse pontine neurons through Slit-Robo Signaling. PLoS Biol 6:e142. CrossRef Medline

Gu H, Zou YR, Rajewsky K (1993) Independent control of immunoglobulin switch recombination at individual switch regions evidenced through Cre-loxP-mediated gene targeting. Cell 73:1155-1164. CrossRef Medline

Hochstim C, Deneen B, Lukaszewicz A, Zhou Q, Anderson DJ (2008) Identification of positionally distinct astrocyte subtypes whose identities are specified by a homeodomain code. Cell 133:510-522. CrossRef Medline

Hunt P, Gulisano M, Cook M, Sham MH, Faiella A, Wilkinson D, Boncinelli E, Krumlauf R (1991) A distinct Hox code for the branchial region of the vertebrate head. Nature 353:861-864. CrossRef Medline

Jang ES, Goldman JE (2011) Pax6 expression is sufficient to induce a neurogenic fate in glial progenitors of the neonatal subventricular zone. PLoS One 6:e20894. CrossRef Medline

Káradóttir R, Hamilton NB, Bakiri Y, Attwell D (2008) Spiking and nonspiking classes of oligodendrocyte precursor glia in CNS white matter. Nat Neurosci [Erratum (2008) 11:851] 11:450-456. CrossRef Medline

Kessaris N, Fogarty M, Iannarelli P, Grist M, Wegner M, Richardson WD (2006) Competing waves of oligodendrocytes in the forebrain and postnatal elimination of an embryonic lineage. Nat Neurosci 9:173-179. CrossRef Medline

Kim SU, McMorris FA, Sprinkle TJ (1984) Immunofluorescence demonstration of $2^{\prime}: 3^{\prime}$-cyclic-nucleotide $3^{\prime}$-phosphodiesterase in cultured oligodendrocytes of mouse, rat, calf and human. Brain Res 300:195-199. Medline

Lampe X, Samad OA, Guiguen A, Matis C, Remacle S, Picard JJ, Rijli FM, Rezsohazy R (2008) An ultraconserved Hox-Pbx responsive element resides in the coding sequence of Hoxa2 and is active in rhombomere 4. Nucleic Acids Res 36:3214-3225. CrossRef Medline

Lumsden A, Krumlauf R (1996) Patterning the vertebrate neuraxis. Science 274:1109-1115. CrossRef Medline

Moens CB, Selleri L (2006) Hox cofactors in vertebrate development. Dev Biol 291:193-206. CrossRef Medline

Narita Y, Rijli FM (2009) Hox genes in neural patterning and circuit formation in the mouse hindbrain. Curr Top Dev Biol 88:139-167. CrossRef Medline

Nicolay DJ, Doucette JR, Nazarali AJ (2004a) Hoxb4 in oligodendrogenesis. Cell Mol Neurobiol 24:357-366. CrossRef Medline

Nicolay DJ, Doucette JR, Nazarali AJ (2004b) Early stages of oligodendrocyte development in the embryonic murine spinal cord proceed normally in the absence of Hoxa2. Glia 48:14-26. CrossRef Medline

Noll E, Miller RH (1993) Oligodendrocyte precursors originate at the ventral ventricular zone dorsal to the ventral midline region in the embryonic rat spinal cord. Development 118:563-573. Medline

Nyabi O, Naessens M, Haigh K, Gembarska A, Goossens S, Maetens M, De Clercq S, Drogat B, Haenebalcke L, Bartunkova S, De Vos I, De Craene B, Karimi M, Berx G, Nagy A, Hilson P, Marine JC, Haigh JJ (2009) Efficient mouse transgenesis using Gateway-compatible ROSA26 locus tar- geting vectors and F1 hybrid ES cells. Nucleic Acids Res 37:e55. CrossRef Medline

Ono K, Fujisawa H, Hirano S, Norita M, Tsumori T, Yasui Y (1997) Early development of the oligodendrocyte in the embryonic chick metencephalon. J Neurosci Res 48:212-225. Medline

Oury F, Murakami Y, Renaud JS, Pasqualetti M, Charnay P, Ren SY, Rijli FM (2006) Hoxa2 and rhombomere dependent development of the mouse facial somatosensory map. Science 313:1408-1413. CrossRef Medline

Pasqualetti M, Ren SY, Poulet M, LeMeur M, Dierich A, Rijli FM (2002) A Hoxa2 knockin allele that expresses EGFP upon conditional Cremediated recombination. Genesis 32:109-111. CrossRef Medline

Patrikios P, Stadelmann C, Kutzelnigg A, Rauschka H, Schmidbauer M, Laursen H, Sorensen PS, Brück W, Lucchinetti C, Lassmann H (2006) Remyelination is extensive in a subset of multiple sclerosis patients. Brain 129:3165-3172. CrossRef Medline

Pattyn A, Vallstedt A, Dias JM, Samad OA, Krumlauf R, Rijli FM, Brunet JF, Ericson J (2003) Coordinated temporal and spatial control of motor neuron and serotonergic neuron generation from a common pool of CNS progenitors. Genes Dev 17:729-737. CrossRef Medline

Pringle NP, Yu WP, Guthrie S, Roelink H, Lumsden A, Peterson AC, Richardson WD (1996) Determination of neuroepithelial cell fate: induction of the oligodendrocyte lineage by ventral midline cells and sonic hedgehog. Dev Biol 177:30-42. CrossRef Medline

Ren SY, Pasqualetti M, Dierich A, Le Meur M, Rijli FM (2002) A Hoxa2 mutant conditional allele generated by Flp- and Cre-mediated recombination. Genesis 32:105-108. CrossRef Medline

Richardson WD, Kessaris N, Pringle N (2006) Oligodendrocyte wars. Nat Rev Neurosci 7:11-18. CrossRef Medline

Rodríguez CI, Buchholz F, Galloway J, Sequerra R, Kasper J, Ayala R, Stewart AF, Dymecki SM (2000) High-efficiency deleter mice show that FLPe is an alternative to Cre-loxP. Nat Genet 25:139-140. CrossRef Medline

Rowitch DH (2004) Glial specification in the vertebrate neural tube. Nat Rev Neurosci 5:409-419. CrossRef Medline

Rowitch DH, Kriegstein AR (2010) Developmental genetics of vertebrate glial-cell specification. Nature 468:214-222. CrossRef Medline

Santagati F, Minoux M, Ren SY, Rijli FM (2005) Temporal requirement of Hoxa2 in cranial neural crest skeletal morphogenesis. Development 132: 4927-4936. CrossRef Medline

Schüller U, Heine VM, Mao J, Kho AT, Dillon AK, Han YG, Huillard E, Sun T, Ligon AH, Qian Y, Ma Q, Alvarez-Bylla A, McMahon AP, Rowditch DH, Ligon KL (2008) Acquisition of granule neuron precursor identity is a critical determinant of progenitor cell competence to form Shhinduced medulloblastoma. Cancer Cell 14:123-134. CrossRef Medline

Spassky N, Goujet-Zalc C, Parmantier E, Olivier C, Martinez S, Ivanova A, Ikenaka K, Macklin W, Cerruti I, Zalc B, Thomas JL (1998) Multiple restricted origin of oligodendrocytes. J Neurosci 18:8331-8343. Medline

Spassky N, Heydon K, Mangatal A, Jankovski A, Olivier C, Queraud-Lesaux F, Goujet-Zalc C, Thomas JL, Zalc B (2001) Sonic hedgehog-dependent emergence of oligodendrocytes in the telencephalon: evidence for a source of oligodendrocytes in the olfactory bulb that is independent of PDGFRalpha signaling. Development 128:4993-5004. Medline

Stolt CC, Lommes P, Sock E, Chaboissier MC, Schedl A, Wegner M (2003) The Sox 9 transcription factor determines glial fate choice in the developing spinal cord. Genes Dev 17:1677-1689. CrossRef Medline

Sugimori M, Nagao M, Bertrand N, Parras CM, Guillemot F, Nakafuku M (2007) Combinatorial actions of patterning and HLH transcription factors in the spatiotemporal control of neurogenesis and gliogenesis in the developing spinal cord. Development 134:1617-1629. CrossRef Medline

Timsit S, Martinez S, Allinquant B, Peyron F, Puelles L, Zalc B (1995) Oligodendrocytes originate in a restricted zone of the embryonic ventral neural tube defined by DM-20 mRNA expression. J Neurosci 15:10121024. Medline

Tripathi RB, Clarke LE, Burzomato V, Kessaris N, Anderson PN, Attwell D, Richardson WD (2011) Dorsally and ventrally derived oligodendrocytes have similar electrical properties but myelinate preferred tracts. J Neurosci 31:6809-6819. CrossRef Medline

Tümpel S, Cambronero F, Ferretti E, Blasi F, Wiedemann LM, Krumlauf R (2007) Expression of Hoxa2 in rhombomere 4 is regulated by a conserved cross-regulatory mechanism dependent upon Hoxb1. Dev Biol 302:646-660. CrossRef Medline

Vallstedt A, Klos JM, Ericson J (2005) Multiple dorsoventral origins of oli- 
godendrocyte generation in the spinal cord and hindbrain. Neuron 45: 55-67. CrossRef Medline
Wegner M (2008) A matter of identity: transcriptional control in oligodendrocytes. J Mol Neurosci 35:3-12. CrossRef Medline 